\title{
El mundo cultural andino en las publicaciones del Seminario de Historia Rural Andina (1968-2015)
}

\author{
Rosaura Andazabal Cayllahua \\ randazabalc@unmsm.edu.pe \\ Universidad Nacional Mayor de San Marcos \\ Facultad de Ciencias Sociales \\ Instituto Seminario de Historia Rural Andina
}

\begin{abstract}
SUMILLA:
El presente texto delinea el aporte historiográfico en torno al mundo cultural andino — con énfasis en los estudios sobre el Arte, la Oralidad y la cosmogonía — con el que el Seminario de Historia Rural Andina ha dado su aporte durante estos cincuenta años de vida académica en favor de las Ciencias Sociales y Humanas. Trabajo que se perfila en tres grandes bloques cronológicos segmentados en estudios de carácter multidisciplinario (1968-2015), uno segundo donde la oralidad pura se trasunta en la serie La Quillca (1975-1993) y un tercer momento desarrollado hacia la década de los noventa con el Proyecto Cuentos Pintados del Perú que se sigue trabajando al presente.

Palabras-clave: Arte Andino; Oralidad Andina; Seminario de Historia Rural Andina; Pablo Macera.

\section{The Andean cultural material in the publications of the Seminario de Historia Rural Andina: 1968-2015}

\begin{abstract}
:
This article discusses the historiographical contributions to Andean cultural topics emphasizing art, oral history and cosmogony. These issues are presented in three phases: 1968-2015: multidisciplinary studies; oral history studies expressed through the "La Quillca" journal series: 1975-1993; Peruvian painted oral history project: 1990-).
\end{abstract}

Keywords: Andean Art; Andean Orality; Seminar of Andean Rural History; Pablo Macera.

\section{Introducción}

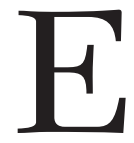
l arte y la oralidad conforman un binomio intrínseco en la cosmovisión de las diferentes culturas que desde épocas remotas hasta hoy coexisten en el mundo andino peruano. Ambas figuran como nexo vinculante de las religiones con las poblaciones, manejado a través de un complejo corpus visual de diversa iconografía que visibiliza a deidades y seres sobrenatura-

1 Esta es una primera aproximación al tema que someramente había tratado ya, en el catálogo de Publicaciones del Seminario (1968-2000), 2010. Y de manera específica me he referido al Proyecto Cuentos Pintados del Perú —-formado y dirigido desde 1994 hasta la fecha por el doctor Pablo Macera—, con ponencias sobre narrativas gráficas del ande peruano que he presentado en Río de Janeiro (2008), en Foz de Iguazú (2013) y en el Coloquio de Lima (2014). 
les, cada una de las cuales figura con voz propia para ejercer dominio sobre su medio circundante: Agua, tierra y aire. Todo lo cual incide de una u otra manera en todos los aspectos del devenir histórico de los pueblos: Economía, política, sociedad y religión, entre los más representativos.

En ese contexto, nuestro primordial objetivo a través de las siguientes líneas es aproximarnos al mundo cultural andino, a través de una parte de la producción bibliográfica del Seminario de Historia Rural Andina (SHRA), centrado sobre todo en el Arte y la Oralidad (1968-2015). ${ }^{2}$ De este modo, nuestra mirada en el presente texto se ajusta al aporte historiográfico que el SHRA ha efectuado sobre el mundo andino, asociado a la imagen y a la palabra como nexo vinculado a la historia nacional en disímiles aspectos (cuadro 1).

Estas temáticas han sido impulsadas por el historiador Pablo Macera Dall'Orso, desde la fundación del SHRA, con su Mapas coloniales de haciendas cuzqueñas (1968). Si bien este es un estudio socio-económico, adjunta una serie de mapas de bella policromía elaborados por agrimensores en el Cusco del siglo XVIII, cuya fineza y detalle en el acabado de cada pintura nos delinea la calidad plástica de sus ejecutores, aún por investigar.

CUADRO 1

\begin{tabular}{|c|c|c|c|c|c|c|c|}
\hline \multirow[b]{2}{*}{ N. ${ }^{\circ}$} & \multirow[b]{2}{*}{$\begin{array}{c}\text { SERIE / } \\
\text { PROYECTO }\end{array}$} & \multirow{2}{*}{\multicolumn{2}{|c|}{ TEMA GENERAL }} & \multirow[b]{2}{*}{ SUBTEMA } & \multirow{2}{*}{$\begin{array}{l}\text { LAPSO CRONOLÓGICO } \\
\text { DE LAS PUBLICACIONES }\end{array}$} & \multicolumn{2}{|c|}{ VINCULACIÓN } \\
\hline & & & & & & IMAGEN & PALABRA \\
\hline \multirow{14}{*}{ I } & \multirow{14}{*}{ 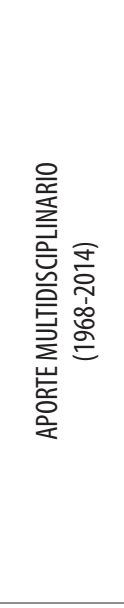 } & \multirow{14}{*}{ 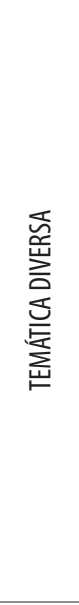 } & 1.1 & Cartografía & $(1968-2015)$ & $X$ & $x$ \\
\hline & & & 1.2 & Medicina & $(1977-2004)$ & --- & $x$ \\
\hline & & & 1.3 & Curanderismo & $(1977-2005)$ & --- & $x$ \\
\hline & & & 1.4 & Dioses y religiosidad popular & $(1980-1993)$ & --- & $x$ \\
\hline & & & 1.5 & Música & $(1979-2003)$ & --- & $x$ \\
\hline & & & 1.6 & Pintura mural & $(1980-1995)$ & --- & $x$ \\
\hline & & & 1.7 & Análisis iconográfico & 2000-2009 & $X$ & $x$ \\
\hline & & & 1.8 & Arte textil & $(1978-1994)$ & $x$ & $x$ \\
\hline & & & 1.9 & Arte Ayacuchano & $(1981-2010)$ & $x$ & $x$ \\
\hline & & & 1.10 & Artesanía & $(1981-2004)$ & $X$ & $X$ \\
\hline & & & 1.11 & Alfarería & $(1981-1982)$ & $x$ & $x$ \\
\hline & & & 1.12 & Juego tradicional & $(1980-1996)$ & $x$ & $x$ \\
\hline & & & 1.13 & Pieles y cueros & $(1998-2000)$ & $x$ & $x$ \\
\hline & & & 1.14 & Gráfica de la plástica andina & $(2001)$ & $x$ & --- \\
\hline \multirow{6}{*}{ II } & \multirow{6}{*}{ 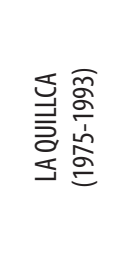 } & \multirow{6}{*}{ 总竞 } & 2.1 & Poncho Prieto & (1975) & --- & $X$ \\
\hline & & & 2.2 & Relatos & (1977) & -- & $x$ \\
\hline & & & 2.3 & El cayhuas y la sierpe & (1979) & -- & $x$ \\
\hline & & & 2.4 & La bruja y el satán & $(1982)$ & --- & $x$ \\
\hline & & & 2.5 & Mi pueblito & $(1983)$ & --- & $x$ \\
\hline & & & 2.6 & Poemas & (1993) & -- & $x$ \\
\hline
\end{tabular}

2 Que, si bien puede abstraerse de las áreas de arqueología y de la historia del arte, así como de los trabajos sobre la Amazonia y la pintura infantil, no incidiremos en ellas, pues cada una ha sido emprendida como materia de estudio por colegas del ISHRA como Amparo Alí, Omar Esquivel, Belén Soria y Juan Zárate respectivamente. 


\begin{tabular}{|c|c|c|c|c|c|c|c|}
\hline \multirow{27}{*}{ III } & \multirow{14}{*}{ 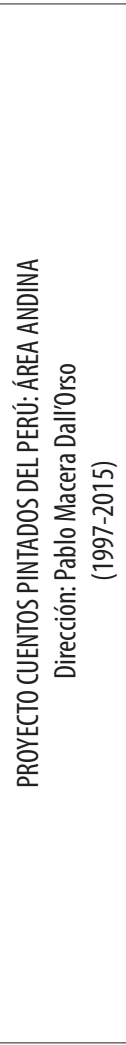 } & \multirow{6}{*}{ 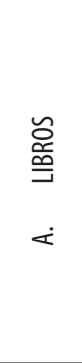 } & A.1 & Ayacucho: Carmelón Berrocal & $\begin{array}{l}1997 \\
\text { GTZ/ MINEDU }\end{array}$ & $x$ & $x$ \\
\hline & & & A.2 & Puno: Félix Condori Vilca & 2002 & $x$ & $x$ \\
\hline & & & A.3 & Áncash: Zoraida Jara & 2003 & $x$ & $x$ \\
\hline & & & A.4 & $\begin{array}{l}\text { Lima: Colegio Nacional Mixto Alto } \\
\text { Huampaní. }\end{array}$ & 2004 & $x$ & $x$ \\
\hline & & & A.5 & $\begin{array}{l}\text { Lima: Colegio Johannes } \\
\text { Gutenberg (El Agustino) }\end{array}$ & 2004 & $x$ & $x$ \\
\hline & & & A.6 & Cusco: Genoveva Núñez & 2012 & $x$ & $x$ \\
\hline & & 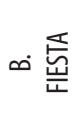 & B.1 & $\begin{array}{l}\text { Cruz de Mayo: Nuestro Señor de } \\
\text { Rasuwillka }^{7}\end{array}$ & $\begin{array}{l}\text { 1997-2016 } \\
\text { Alto Huampaní, } \\
\text { Chaclacayo }\end{array}$ & $x$ & $x$ \\
\hline & & & C.1 & $\begin{array}{l}\text { Carmelón Berrocal. Exposición } \\
\text { Homenaje }\end{array}$ & 1998 / MNCP & $x$ & $x$ \\
\hline & & & C.2 & Imágenes e Imagineros & $\begin{array}{l}\text { Dic 1998- Ene } 1999 \text { IFEA/ } \\
\text { Sala Cultura Banco Wiesse }\end{array}$ & $x$ & $x$ \\
\hline & & & C.3 & Vivencia Aimara & $\begin{array}{l}2000 \text { / Museo de Arte San } \\
\text { Marcos (MASM) }\end{array}$ & $x$ & $x$ \\
\hline & & & C.4 & Visiones de Sarhua & $\begin{array}{l}2000 \text { / Sala de Arte Diario } \\
\text { El Peruano }\end{array}$ & $x$ & $x$ \\
\hline & & & C.5 & $\begin{array}{l}\text { Juguetes tradicionales del valle } \\
\text { del Mantaro }\end{array}$ & $\begin{array}{l}\text { Dic 2000-Ene 2001/ } \\
\text { MASM }\end{array}$ & $x$ & $x$ \\
\hline & & & C.6 & $\begin{array}{l}\text { Jesús Urbano Rojas: narrador de } \\
\text { historias y cuentos }\end{array}$ & $\begin{array}{l}2001 \\
\text { MNCP }\end{array}$ & $x$ & $x$ \\
\hline & & & C.7 & $\begin{array}{l}\text { Madres y Niñas (Colectiva Ande y } \\
\text { Amazonia) }\end{array}$ & $\begin{array}{l}\text { Dic 2001-Ene } 2002 \\
\text { UNMSM/ UNESCO }\end{array}$ & $x$ & $x$ \\
\hline & & & C.8 & $\begin{array}{l}\text { Félix Condori: Lagos, demonios y } \\
\text { serpientes }\end{array}$ & 2002 & $x$ & $x$ \\
\hline & & & C.9 & Zoraida Jara: Testimonio de Vida & 2003 & $x$ & $x$ \\
\hline & & & C.10 & Este cuentito que he pintado & $\begin{array}{l}\text { 2004/ Colegio Johannes } \\
\text { Gutenberg }\end{array}$ & $x$ & $x$ \\
\hline & & & C.11 & Tradición oral de Ollantaytambo & 2006 & $x$ & $x$ \\
\hline & & & C.12 & $\begin{array}{l}\text { Ritualidad. Fotografía de Fredy } \\
\text { Huamán Mallqui }\end{array}$ & 2008 & $x$ & $x$ \\
\hline & & & C.13 & $\begin{array}{l}\text { El legado del Huayli. Los Tineo y la } \\
\text { cerámica ayacuchana }\end{array}$ & 2011 & $x$ & $x$ \\
\hline & & 状 & C.14 & $\begin{array}{l}\text { Sumaq Qaramanta/ De la bonita } \\
\text { piel: peletería y talabartería } \\
\text { ayacuchana }\end{array}$ & 2013 & $x$ & $x$ \\
\hline & & $\begin{array}{l}\text { 흔 } \\
\text { 응 } \\
\text { 춥 }\end{array}$ & C.15 & $\begin{array}{l}\text { Homenaje a don Jesús Urbano } \\
\text { Rojas. Tras las huellas del } \\
\text { Maestro: Retablos e Imaginería } \\
\text { de Genoveva Núnez Herrera. }\end{array}$ & 2015 & $x$ & $x$ \\
\hline & & & D.1 & $\begin{array}{l}\text { Calendario 1998: Carmelón } \\
\text { Berrocal }\end{array}$ & $\begin{array}{l}\text { 1998/ Tarea Asociación } \\
\text { Gráfica Educativa (TAGE) }\end{array}$ & $x$ & $x$ \\
\hline & & 气 요 & D.2 & $\begin{array}{l}\text { Calendario 2002: Félix Condori/ } \\
\text { Zoraida Jara/ Genoveva Núñez }\end{array}$ & 2002 / TAGE & $x$ & $x$ \\
\hline & & 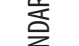 & D.3 & Calendario 2002: Zoraida Jara. & 2002 & $x$ & $x$ \\
\hline & & 岕 & D.4 & $\begin{array}{l}\text { Calendario 2005: Félix Condori } \\
\text { Vilca }\end{array}$ & 2005/TAGE & $x$ & $x$ \\
\hline & & & D.5 & $\begin{array}{l}\text { Calendario 2009: Aprendiendo } \\
\text { saberes de nuestra diversidad } \\
\text { cultural y lingüística }\end{array}$ & 2009/ CARE Perú & $x$ & $x$ \\
\hline
\end{tabular}

${ }^{1}$ Sobre el tema veáse el artículo de Andazabal, 2015. 
Seguido a la imagen, la aguda visión y sensibilidad del historiador lo lleva a formar la serie La Quillca en la década de 1970, para dar espacio a la oralidad pura de las gentes del ande norteño, como veremos más adelante. En paralelo, Macera llevó a cabo un segundo grupo de investigaciones multidisciplinarias donde es posible abstraer la trasmisión de la palabra asociada al arte de la pintura (murales, tablas de Sarhua, etc.), de la talla en madera y en Niño Rumi (piedra de Huamanga o alabastro), de las pieles y cueros (repujado y calado), de la cerámica, del textil, de los mates y cuernos burilados (cornuplastía), de los cajones San Marcos y los retablos, de las pasta wawas y los caballitos de badana, junto a otros estudios de análisis iconográfico.

Pero es en el proyecto Cuentos Pintados del Perú iniciado en 1994, donde Pablo Macera efectúa una verdadera proeza, al darle un espacio tangible y efectivo a las narrativas gráficas del mundo andino, iniciado con Carmelón Berrocal, un excepcional pintor del distrito de Sarhua, en las alturas de la provincia de Víctor Fajardo, en el departamento de Ayacucho. El proyecto de Macera buscaba darle un espacio físico en la Universidad Nacional Mayor de San Marcos (UNMSM) a artistas del Ande para formar un gran archivo de la diversidad de saberes de cada una de las culturas revaloradas en sus lenguas de origen: El Quechua y el Aimara. Lo cual, como se verá más adelante, ha cumplido sus objetivos de preservación, difusión y conocimiento tanto para el mundo académico, para estudiantes en edad escolar y universitario, como para la sociedad en general. Ello mediante publicaciones educativas interculturales en edición bilingüe, exposiciones de arte, calendarios, tarjetas, afiches, dípticos y catálogos. Además se promovió junto a todos los miembros del SHRA la festividad sincrético religiosa de la Cruz de Nuestro Señor (Apu) de Rasuwillka, a iniciativa de su gestor, el retablista huantino Jesús Urbano Rojas, la cual se viene celebrando desde 1998, cada 3 de mayo en Alto Huampaní, Chaclacayo.

\section{Aporte multidisciplinario (1968-2015). Temática diversa}

\subsection{Cartografía}

Dentro de este grupo de investigaciones donde confluye el aporte de varias ramas de las Ciencias Sociales al estudio del arte y la oralidad andina, existe un conjunto de estudios asociados a la cartografía colonial donde es posible visibilizar a los artistas que a mano alzada levantaron planos, mapas y caminos en documentos sobre litigios por tierras y aguas llevados a cabo en las audiencias. En este contexto se perfilan las publicaciones que sobre el Perú, Bolivia, Ecuador y Chile aparecen en el SHRA, basados en fuentes documentales del Archivo General de la Nación del Perú (AGN), del Archivo Arzobispal de Lima y del Archivo Nacional de Sucre en Bolivia, en base a una prolija selección efectuada por Pablo Macera. ${ }^{3}$

La otorgación de títulos por mercedes de tierras entre los siglos XVI y XVII, que dieron origen a las encomiendas en todo el territorio, propiciaron no sólo el usufructo de sus legítimos dueños sino también constantes pleitos de tierras por linderos mal mensurados. Estos pleitos ubicados en las Audiencias de Lima y Quito desde el siglo XVII llegaron a su punto más álgido en el siglo XVIII, confrontando a indios y criollos, clérigos criollos y laicos, funcionarios de la administración colonial y a las órdenes religiosas.

3 Estos materiales de trabajo se tenían en reserva en el archivo del SHRA, los cuales eran distribuidos por Pablo Macera al área de investigación para su procesamiento (ordenamiento cronológico y geográfico, paleografía y análisis de las fuentes) y estudio. 
1.1.1 Los Agrimensores y el arte del trazo, la línea y la pintura en los planos y mapas.

Una interesante veta por trabajar, a partir de este conjunto de investigaciones, es el referido a la figura del agrimensor en su papel de artista. El agrimensor va más allá del dibujo lineal para levantar planos y mapas a escala de caminos, puentes, ríos, cerros y promontorios; agrega además el color para destacar en el escenario rural agrario, la simplicidad u ornamentada estructura arquitectónica de las casas, corrales, capillas y haciendas, así como la representación de la flora y fauna local.

\subsubsection{El espacio geográfico.}

La representación plástica juega un papel de vital importancia en estos informes económicos de tipo agrario, donde por lo general se litiga por el agua y la tierra. Ello es evidente en el estudio ya mencionado de Pablo Macera, Mapas coloniales de haciendas cuzqueñas, que contiene un conjunto de mapas y planos de haciendas que se complementan con documentos que tratan de la estructura, funcionamiento, comercialización y la mano de obra empleada en este tipo de empresa. Así, se registran tanto en el dibujo como en la documentación datos de importancia de algunas plantaciones costeñas, cañaverales serranos, chacras de pan llevar y estancias de ganado. ${ }^{4}$ Esa es la línea de trabajo que han continuado en el SHRA Omar Rojas, Rosaura Andazabal, Victoria Espinoza y Luz Peralta. ${ }^{5}$

Al igual que en el Perú, en la Bolivia de fines del siglo XVIII y pasada la segunda mitad del siglo XIX, las autoridades civiles, eclesiásticas y militares habían ordenado se hiciesen expediciones para que trazaran rutas de acceso a estos caminos para defender las tierras de las invasiones. Producto de ello se formaron para las zonas de Cochabamba, Mamoré, Santa Cruz, La Paz, Cobija, Inquisivi, Yaco, Oruro y Porco, copiosas relaciones de mapas, caminos, planos, puentes, divisiones de curatos y relaciones de viajes. A ello se agrega series estadísticas de Mojos y Chiquitos y referencias de aperturas de caminos en Mojos, Cochabamba y el Oriente boliviano. Las fuentes bolivianas reiteran el importante papel que les cupo a los agrimensores en los conflictos por la delineación territorial como se evidencia en los mapas de tierras de los indios del Chaqui, en Potosí de mediados del siglo XIX. Esta población a través de la formación de minifundios logra detener el plan expansionista que la clase criolla había elaborado para expropiarles sus tierras bajo la forma de pagos por composición. En esa línea se sitúan las investigaciones que han trabajado Nadia Carnero, ${ }^{6}$ Pablo Macera ${ }^{7}$ y Santiago Tácunan. ${ }^{8}$
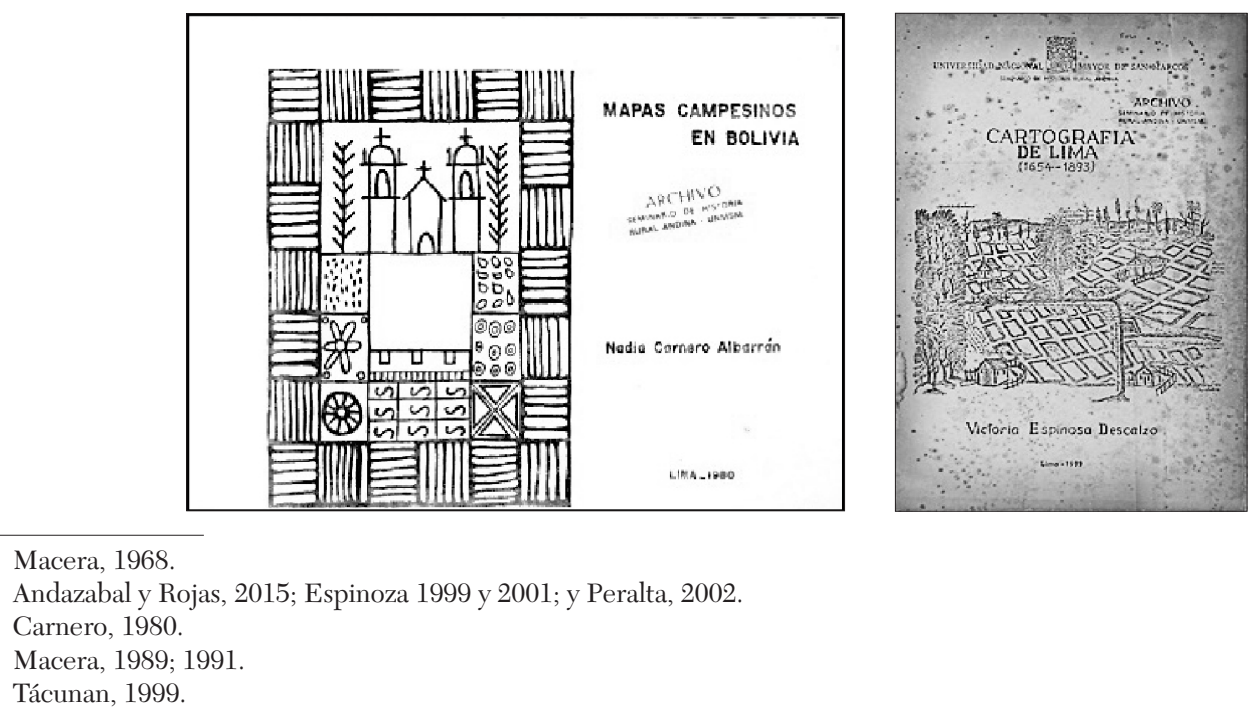
Para el siglo XVIII ecuatoriano, dos trabajos abordan pleitos coloniales. El librado por las tierras de Anla y Cochecarangue que enfrentó al convento de las Mercedes con don Gabriel Zuleta de Reales, trabajado por Rosaura Andazabal. ${ }^{9} \mathrm{Y}$, el pleito entre Francisco Román, un vecino de Cuenca, en contra de la "sistemática invasión a sus tierras en Burgay por el mercedario Fray Joseph Palacios", trabajado por Omar Rojas. ${ }^{10}$ Finalmente, la investigación de Alejandro Salinas y Belén Soria, recogen dos litigios para el siglo XVIII chileno entre hacendados y religiosos por cuestión de linderos en las estancias de Puangue y Renca siempre vinculada a los planos artísticos levantados por los agrimensores. Documentación que además compone "registros de tipos y precios de cultivos, tasaciones de las unidades agrícolas, junto a mapas y planos de las estancias en disputa”. ${ }^{11}$

\subsection{Medicina}

La Historia y la Antropología nos acercan a la trasmisión oral sobre la medicina tradicional andina que, por siglos ha pervivido como parte de la cosmogonía de los pueblos del ande peruano, asociado al poder de los Apus (cerros dioses), del cosmos y al uso de plantas o animales que el medio geográfico ofrece.

Para el siglo XVII, Luis Basto Girón sobre la base documental de hechicerías e idolatrías aborda aspectos de salud y patología, métodos terapéuticos, etiología y sintomatología de las enfermedades, etc. Observa la pugna entre las autoridades eclesiásticas por el control de las campañas de conversión al catolicismo y las sanciones aplicadas a los que practicaban la medicina natural en el Corregimiento del Cercado de Lima, incluidas Jauja, Vico y Pasco; así como el valle de Santa que pertenecía al Corregimiento de Trujillo. ${ }^{12}$

En 1980 el SHRA reeditó el Libro de medicinas y cirugía. Para el uso de los pobres. Con su recetario al final $(1800)^{13}$ del médico francés Martín Delgar donde, como resultado de sus pesquisas sobre la medicina tradicional en el ande peruano, proporciona una vasta lista de minerales y de la flora y fauna peruana para preparar medicamentos que por entonces le dieron óptimos resultados.

Desde el lado de la etnografía, y empleando como recurso las crónicas del siglo XVI-XVIII en idioma quechua y español, Fabiola Chávez rescata información sobre el infante y el ciclo vital reproductivo de la mujer, desde la menarquía hasta cuidados post-parto. Tanto a nivel de prácticas curanderiles (ritos, fitoterapia, etc.) como de síndromes culturales (ojeo, pérdida de la sombra, etc.) que pueden incidir durante la menstruación, el embarazo, el parto y el post-parto. Lo cual complementa con el resultado del trabajo de campo con mujeres del ande piurano. ${ }^{14}$

Desde la observación y análisis antropológico in situ tanto en la provincia de Cangallo (Ayacucho), Apurímac, Huancavelica, Junín y de migrantes andinos asentados en Lima, el estudio de Lauro Hinostroza descubre cómo el entorno cosmogónico tipifica las enfermedades de acuerdo a la trasgresión de los valores morales. ${ }^{15}$ En la misma dirección Fabiola Chávez plantea el análisis alternando la mitología, la arqueología y la medicina tradicional, incorporado a la fiesta de carácter religioso, agrícola y de fertilidad. ${ }^{16}$

\footnotetext{
Andazabal, 1994.

Rojas, 1994.

Salinas y Soria, 1994.

Basto, 1977.

Delgar, 1980.

Chávez, 2004

Hinostroza, 1988.

Chávez, 2005.
} 


\subsection{Curanderismo}

En el mágico mundo del curanderismo norteño, destaca en la ciudad de Trujillo la figura de don Eduardo Wilfredo Calderón Palomino, conocido como Tuno el curandero. José Gushiken encuentra que los elementos centrales en la curación, saber ancestral proveniente de la tradición familiar, se halla vinculado a la terapia con el cuy y a las fuerzas energéticas de las Lagunas de las Huaringas. ${ }^{17}$

El antropólogo Javier Macera trata el mismo tema en torno a las comunidades de Mórrope y Salas asociado al universo mágico religioso que sustenta la terapia curativa de los curanderos y el conocimiento botánico medicinal que tienen y aplican a la población. La eficacia terapéutica proviene de sus ancestros, de cuyos aciertos dependerá su prestigio y por ende el incremento de sus pacientes. Aunque el curandero no ocupa la misma posición social que tuvo el chamán goza a nivel local de una posición económico-social de importancia y prestigio. ${ }^{18}$

Complementa a los estudios anteriores sobre el curanderismo norteño, el Glosario que para el departamento de Piura ha trabajado Mario Polia en algo más de tres décadas recogiendo de la información oral de los maestros curanderos y curanderas del ande piurano, palabras referidas a la cosmovisión, a la ritualidad curanderil, al mundo mítico y a la medicina tradicional. ${ }^{19}$

\subsection{Dioses y religiosidad popular}

Un punto coincidente en la trasmisión oral y en la ritualidad andina, es sin duda la coexistencia de la religión andina politeísta y la religión católica traída por los españoles bajo la imponente figura de Cristo crucificado. Los estudios publicados en el SHRA en torno a este tipo de religiosidad son abordados desde la Antropología, la etnografía y la Sociología.

El culto popular en el escenario andino reside en el orden cósmico de los dioses tutelares de mayor o menor jerarquía, que definen el calendario ritual del trabajo y la vida cotidiana, en clara armonía con el entorno geográfico. Marcando una clara discordancia con el fenómeno religioso cristiano. ${ }^{20}$ Asimismo, dicha pervivencia del culto religioso al dios precolombino coexistente con las divinidades locales de menor jerarquía, se trasunta en las formas del "pagapu" al "Tayta Wamani” que aún se practican en los rituales ganadero, agrícola y en la medicina andina ayacuchana. ${ }^{21}$ Prácticas rituales de protección a los dioses andinos trasmitidas por generaciones, como el que vive aún en la estructura mental religiosa de los pobladores de Suyu (Sicuani, Cusco), en cuya Waka principal pernocta la figura de su deidad bajo la forma iconográfica de una estela lítica, la cual coexiste desde antes del siglo XVI con el felino fitomorfo y la sierpe bicéfala cómo deidades locales de menor jerarquía. ${ }^{22}$

Dioses, rituales y prácticas que abundan en los fondos documentales signados como extirpación de idolatrías que, en los archivos históricos eclesiásticos existen tanto en Ayacucho — donde el estado colonial a través de la Iglesia buscaba reglamentar el culto divino y la administración re$\operatorname{ligiosa}^{23}$ - cómo en el pueblo de Carampoma (Huarochirí, Lima), donde aún se invoca a Yyancuri

\footnotetext{
17 Gushiken, 1977.

18 Macera, 2004.

19 Polia, 2005.

20 Morande, 1980

21 Arroyo, 1987.

22 Valencia, 1987

23 Arroyo, 1988.
} 
y Huari — creadores de la aparición de quebradas, valles y cerros - en la fiesta de la Champería, vinculada a creencias asociadas a las estrellas. ${ }^{24}$

\subsection{Música}

En la biografía de un músico, en las fiestas, en las danzas y en los takis o cantos se reitera esa ligazón constante con el cosmos circundante de cada una de las sociedades. En el SHRA este tema se aborda en investigaciones etnográficas, antropológicas e históricas.

José Gushiken retrata la vida del excepcional violinista Máximo Damián, desde su niñez en San Diego de Isua (Lucanas, Ayacucho) hasta su vida cómo migrante en la Lima de la década de 1960, donde enfrenta la discriminación de su lengua quechua en el ámbito laboral. No obstante, su habilidad y destreza con el violín lo posiciona en el escenario cultural en la UNMSM y en la Casa de la Cultura del Instituto Nacional de Cultura, gracias al aprecio y difusión que hace José María Arguedas sobre su obra musical. En la biografía de Máximo Damián está presente sus recuerdos sobre las costumbres de su pueblo, sobre los danzantes de tijeras, las fiestas de carnavales y patronales, como también a los rituales asociados al agua y al ganado, pero sobre todo en torno al conocimiento de la cosmogonía de la provincia de Lucanas (Ayacucho) narrado a través de mitos, sueños y cuentos. ${ }^{25}$
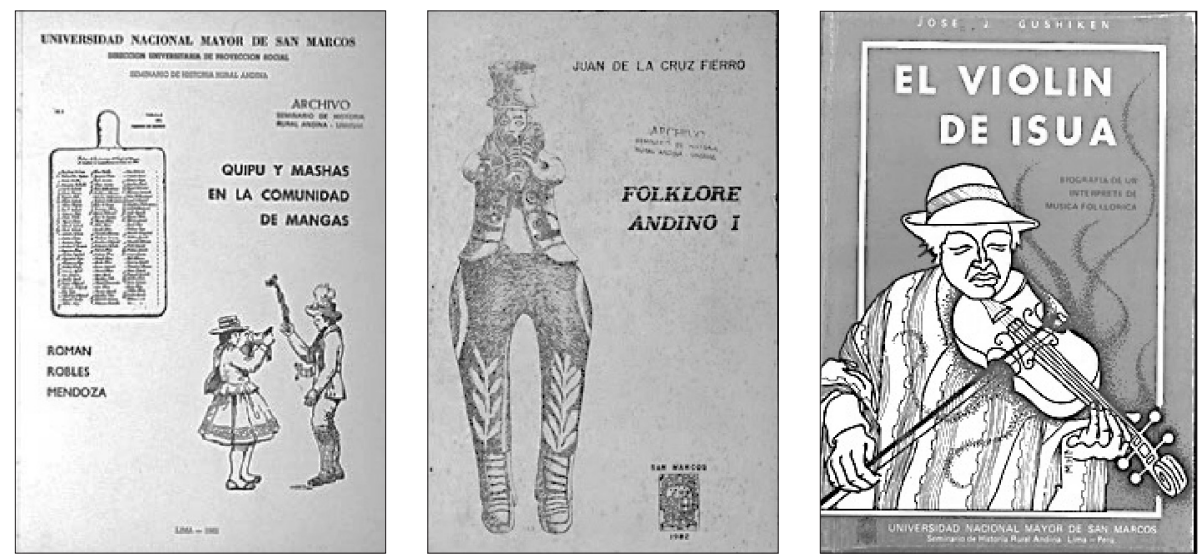

Por otro lado, un conjunto de publicaciones de Arqueología, Antropología e Historia destacan la oralidad trasmitida a través de las fiestas y en las danzas rituales como la Fiesta del Niño perdido en Huancavelica; ${ }^{26}$ de la Champería o ritual festivo al agua en San Pedro de Casta (Huarochirí, Lima); ${ }^{27}$ de los danzaq de tijeras, de la Huanca danza, del Paurán, del Huaylas, del Corcovado y de los carnavales en el valle de Yanamarca en Jauja. ${ }^{28}$ Pero también se perfila otro grupo donde coexiste la religión andina y la fe católica: la fiesta de los Mashas, de la comunidad de Mangas en Áncash, ${ }^{29}$ el de la Virgen Candelaria en Arequipa; ${ }^{30}$ y la danza de los morenos y cruceros de Huaylillas situados en una región ancestral común entre la cuenca del Lago Titicaca y el norte grande

24 Gushiken, 1993.

25 Gushiken, 1979.

26 Carbajal, 1981.

27 Echeandía, 1981; 2003

28 De la Cruz, 1982.

29 Robles, 1982.

30 Motta, 1985. 
de Chile. ${ }^{31}$ Paralelamente, están los cantos de origen prehispánico y colonial. En el primer caso se halla el taki tushuy o baile cántico denominado Jerga Kumu del distrito de Yauyos en Jauja ${ }^{32}$ y, por otro lado, están los himnos quechuas ${ }^{33}$ vinculado a la fe católica y el proceso evangelizador colonial.

\subsection{Pintura mural}

El interés de Pablo Macera por el estudio de la pintura mural como expresión oral y artística data desde la fundación del SHRA. Allí tenemos las publicaciones sobre Tadeo Escalante y los murales de Acomayo (1974), el arte mural cuzqueño (1975), La pintura mural andina, siglos XVI- XIX (1993) y los murales de Rapaz (1995), entre otros.

En su libro Arte y lucha social: Los murales de Ambaná (Bolivia) (1980), Pablo Macera afirma que en las poblaciones andinas ha perdurado la idea de emplear las paredes como vía de expresión ideológica. En esta investigación histórica, da cuenta que el núcleo artístico social del pueblo de Ambaná inserta a otras poblaciones periféricas a ella, aunque con características estéticas y técnicas murales diferenciadas. El área de estudio corresponde a los murales laicos y privados de Ambaná entre los siglos XIX y XX, cuyo radio geográfico se distribuye en casas de vecinos (Casa Bonifacio y Machicado), fincas (Chinchipata), haciendas (Tetejone), campesinos (Familias Chiara y Nina) y poblanos (Casa Efraín Rengel). ${ }^{34}$

Hacia la década del noventa, Macera consigue que la UNESCO auspicie su proyecto Encuesta Pintura Mural del Perú. Así, en el SHRA varios investigadores fueron convoca-

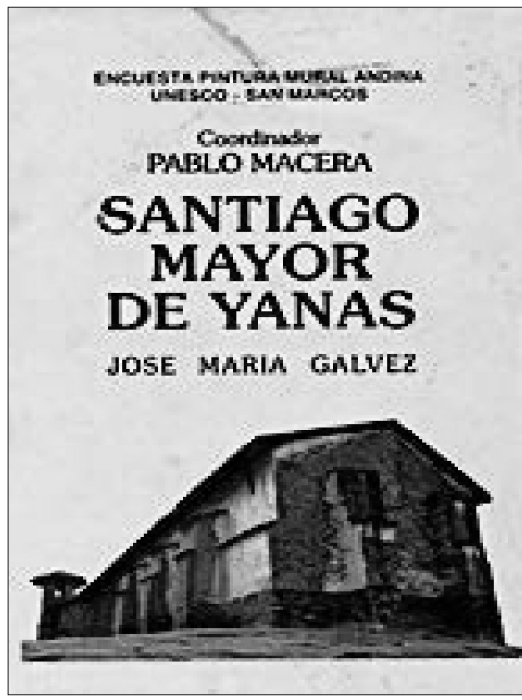
dos para investigar pintura mural en el sur del ande peruano y en la sierra norte. No todos los resultados de esta encuesta fueron alentadores. Así, en el rastreo efectuado por Rosaura Andazabal en la provincia de Sucre, en el departamento de Ayacucho, la "modernidad" de ladrillo y cemento había derruido ya todo vestigio ancestral.

Aunque el panorama desalentador alcanzara también a zonas como Andahuaylas (Apurímac) y a la provincia de Espinar en el Cusco, el proyecto alcanzó objetivos significativos en el recojo de información oral y visual de algunos de estos circuitos. Rodas, por ejemplo, encuentra pinturas murales en las haciendas: Casa Néstor Canales, Misares, México Pozo y Urquizo, circunscritos a los pueblos de Andarapa y Turpo. Las representaciones estéticas signan un trabajo contemporáneo en las que destacan alegorías de flores, signos eucarísticos, adornos, un niño y un cóndor. Los de mayor importancia fueron los registrados en Misares (figura del cóndor asociado a Tacna y Arica; y una alegoría de la campaña de Napoleón en Rusia) y Urquizo (Escenas de folklore que aluden al baile de los negritos y los tocadores de waqrapuku). ${ }^{35}$

Para la provincia de Espinar (Cusco), luego de la ardua tarea de visitar 62 iglesias, Alicia Quirita solo pudo registrar vestigios de pintura mural en las iglesias de Coporaque, Pichigua y Sillota.

\footnotetext{
1 Motta, 1987.

32 Mallma, 1989.

Lira, 1988 .

Macera, 1980.

5 Rodas, 1994.
} 
En Coporaque halla siete conjuntos diferenciados de murales en pisos y zócalos, dentro de un registro convencional de frutas y flores, otros que corresponden a figuras religiosas de San Sebastián, Santa Bárbara y la Virgen del Rosario, las que podrían comprender a la "última etapa del muralismo colonial cusqueño vinculado a estilos como las de Tadeo Escalante”. 36

Un tercer conjunto de pintura mural es el que encuentran José María Gálvez y Pablo Macera en el templo de Santiago Mayor de Yanas, en la alta cordillera de Áncash, en la provincia de Huari. El templo presenta en el presbiterio a Evangelistas y Santos, en otros ambientes lleva impreso muralismo popular y murales del siglo XVII, simbología de los dominicos, de los Evangelistas del siglo XVI y de Santa Rosa del siglo XVII. Macera y Gálvez señalan que: "Santiago de Yanas puede ser considerado un testimonio temprano de la colonización europea en los Andes del Perú." ${ }^{7}$

\subsection{Análisis iconográfico}

Los rasgos culturales tradicionales dentro de los espacios visuales manejados en la percepción del hombre andino, tanto en su medio original de desarrollo, como también cuando se traslada a zonas urbanas como Lima, pueden verse en los trabajos de Karina Cuentas sobre Esquemas Visuales, y el de Arturo Mallma y Rufino Torres sobre el Origen e interpretación iconográfica del símbolo de la UNCP.

Cuentas analiza la iconografía simbólica (asociada al medio geo-demográfico, a las costumbres, mitos y tradiciones) dentro del marco del diseño gráfico, con el que elabora materiales didácticos para adultos y escolares de la zona rural de Pomacocha (Huánuco) y en una zona urbano marginal de la periferia limeña, ambas vinculadas a campañas preventivas de salud como la uta y la diarrea. En el caso de la uta, la disposición de los íconos discurre a la manera de un calendario agrícola andino asociado al cielo, a la tierra y al agua. Diseño que varía para la zona urbana, donde el mensaje aflora en una agresiva segmentación de los elementos a emitir, como resultante de la fusión y/o aceptación de los nuevos patrones culturales que se incorporan a la percepción del migrante andino ${ }^{38}$

Desde la Antropología y la Arqueología la investigación de Mallma y Torres delinea el proceso histórico de la antigua Universidad Comunal del Centro (UCCP) inicialmente creada en Acolla (Jauja) y más tarde trasladada a Huancayo bajo el nombre de Universidad Nacional del Centro del Perú. Ambos centran su interés en el análisis de la iconografía del logotipo, la que lleva impresa la representación gráfica de la figura antropomorfa de un personaje con báculos, que fue tomada de un tupu de oro y plata que Sergio Quijada Jara donó al doctor Javier Pulgar Vidal, en su calidad de primer rector de esta casa de estudios. Inicialmente asociada a Huallallo Carguincho, esta correspondería más bien a una deidad contextualizada en períodos más antiguos de origen tiahuanaquense y/o Wari. ${ }^{39}$

\subsection{Arte textil}

Las publicaciones del SHRA en torno al desarrollo del arte textil, abarca un amplio espacio geográfico que va desde Cajamarca al norte del Perú, hasta Huancavelica, Andahuaylas y Puno en el

36 Quirita, 1995.

37 Gálvez y Macera, 1995.

38 Cuentas, 2000

39 Mallma y Torres, 2009. 
eje sur andino. El espacio temporal es igual de amplio, desde antes del apogeo Inca al siglo XX. En ese perfil se sitúan las publicaciones antropológicas de Guillermo Sayán, de Juan Echeandia, de Fredy Rodas, y de Haydeé Quiroz, ${ }^{40}$ entre otros,

Simbolismo y oralidad entrelazan los textiles (fajas, rebozos, ponchos, faldas, etc.) en una posible escritura nemotécnica, donde una alegoría de diseños aluden al entorno natural y cosmogónico que adornan las prendas, bajo diversas formas -ríos, lagunas, estrellas, árboles, flores, serpientes, mariposas, aves, perros, pumas y zorros- que los tejedores de hoy en día saben aún descifrar. Como Los Maquitos de Huancavelica — de los anexos de Lircay, Pachaclla, Acobamba, Chopca, Chacarilla, Ambato, Yauli, Paucará y Salcabamba - cuyo uso correspondería a épocas del reino Ancara en el siglo XVI, sometidos por los Incas en condición de mitmas. ${ }^{41}$
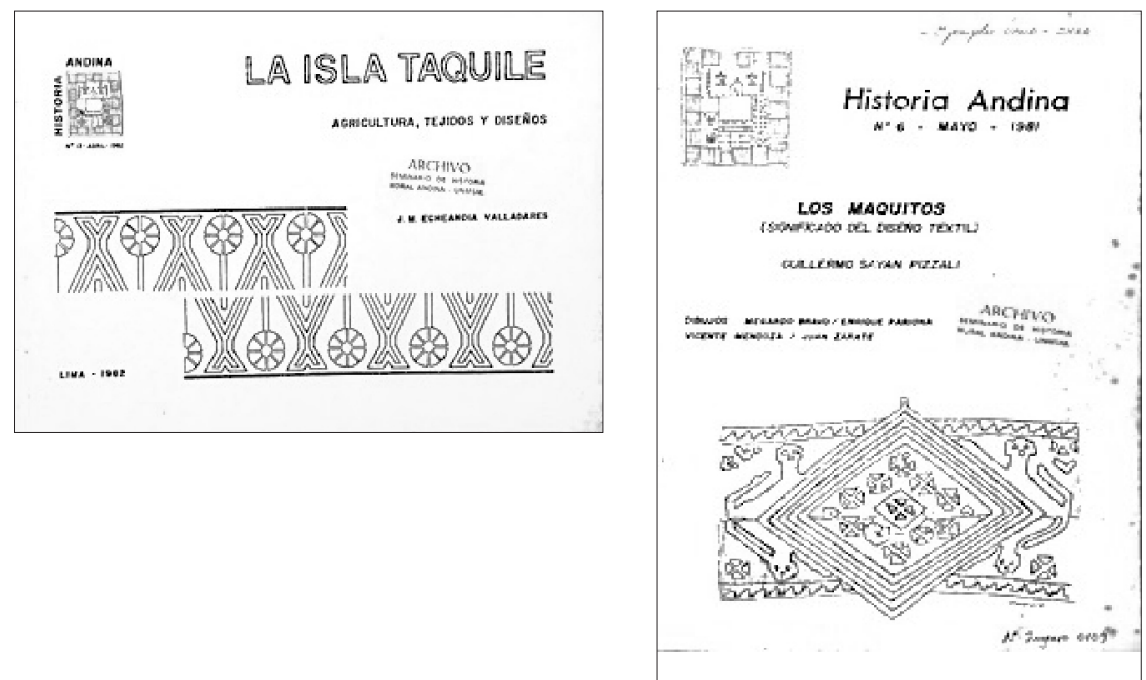

De similar forma destacan los diseños-escritura, en los finos mantos de Taquile (Puno), asociados al ciclo agrícola, a la vida cotidiana y al desarrollo genealógico de las familias. Aunque ya en la década de los ochenta capitales externos habían incidido en los cambios ocurridos en la simbología y en las técnicas de productividad artesanal de esta isla. ${ }^{42}$

En el caso de los tejidos tradicionales de la provincia de Andahuaylas, la estructura iconográfica de sus textiles registran la historia, la genealogía y la cosmogonía propia que, Fredy Rodas rescata de un conjunto de cincuenta y tres diseños hallados en mantas, ponchos y fajas de los distritos de Huancarama, Pacucha, Kishuará, San Jerónimo, Santa María de Chicmo, Huancaray, Turpo, Umamarca y Andahuaylas. ${ }^{43}$

\subsection{Arte de Ayacucho}

Ubicamos en las publicaciones del SHRA, varios estudios referidos a los retablos andinos, a la talla en piedra de Huamanga y en madera, a las tablas de Sarhua; figurando también las biografías de excepcionales artistas como Joaquín López Antay y el de su discípulo Jesús Urbano Rojas; así como

40 Quiroz y varios, 1978.

41 Sayan, 1981.

42 Echeandía, 1982

43 Rodas, 1994. 
la del pintor Carmelón Berrocal. Existe asimismo el registro fotográfico que el lente de Fredy Huamán Mallqui captura de varios escenarios de Ayacucho y Apurímac.

\subsubsection{Los Cajones San Marcos, los retablos, los artífices}

Pablo Macera estudia la ruta histórica del retablo, desde los altares de las iglesias, patios, corredores o antesalas de convento hasta los retablos andinos de fines del siglo XVII hallados en Canas, los cuales pudieron haber coexistido con los modelos huamanguinos. No obstante, los modelos se distanciaron del europeo, mostrando una técnica como una temática propia. Macera observa varios aspectos que cumplió el retablo en la sociedad surandina: su importante papel en el proceso de catequización, su uso como altares portátiles que otorgaron al usuario andino cierta independencia de culto incidiendo en el debilitamiento del poder de la Iglesia, como la posesión del retablo y el material del que estaba hecho denotaba status económico. Este apogeo alcanzado sobre todo por el San

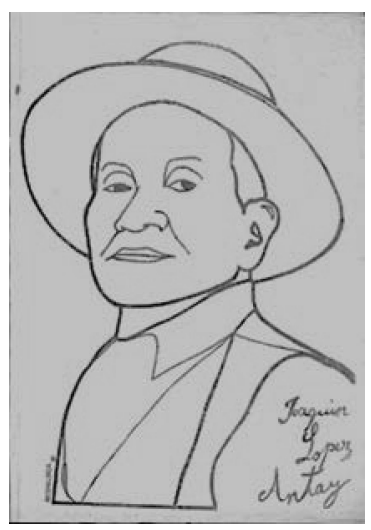
Marcos huamanguino, entra en declive hacia la década de 1940 en que es sustituido con éxito por retablos escénicos, como producto del contacto entre el movimiento indigenista venido de Lima y los artesanos de Huamanga. ${ }^{44}$

Pablo Macera también delineó las rutas filiales de origen en torno al funcionamiento de los talleres ayacuchanos dedicados a la manufactura de los cajones San Marcos, retablos e imaginería. En ese contexto se inscribe la obra de don Joaquín López Antay (1897-1981), cuya vena artística proviene de dos ramas cronológicas de producción. La primera compuesta por Manuela Momediano y Esteban Antay en el siglo XIX y la segunda que nace de los matrimonios de Gregoria Jiménez (Baldeón/ Jiménez/ Núñez). Descendiendo Joaquín López Antay de la primera rama filial, innova su tradición con rasgos diferenciados en la temática, en el uso cromático y en el manejo de los íconos externos. Cada una de las cuales lleva una carga semántica y estética para expresar su compleja cosmogonía, como la vida misma. ${ }^{45}$

La tesis de las antropólogas Felícita Prada y María Vergara, desde la perspectiva de la Escuela Marxista, analiza el contexto laboral, los circuitos económicos y los problemas que afrontan los artesanos del retablo de la periferia huamanguina. Centran su estudio en el cambio del retablo religioso al retablo etnográfico, donde se conjugan principios utilitarios y estéticos; además de observar la trasmisión de conocimientos ancestrales, junto a vivencias contemporáneas, como también a la preservación de concepciones mentales propias con las que renuevan sus medios de producción. ${ }^{46}$

Finalmente, está la publicación que a manera de catálogo destaca una breve nota biográfica de Jesús Urbano Rojas, así como la composición iconográfica pormenorizada de cada uno de los retablos que se preparó para los visitantes del XXXIII Festival Internacional de Aarhus, Dinamarca, a la que fue invitado en $1997 .{ }^{47}$

\footnotetext{
44 Macera, 1981.

45 Macera, 1981.

46 Prada y Vergara, 1984

47 Andazabal, 1997.
} 


\subsubsection{Talla en Niño Rumi y en madera}

Los estudios de Flor ${ }^{48}$ y Mary Luján, ${ }^{49}$ si bien desarrollan con mayor énfasis el aspecto económico de la productividad tanto de la talla en piedra de Huamanga como en madera, también desarrollan en parte el simbolismo y la oralidad que los artistas le imprimen a cada de una de sus obras. Hacen uso de la metodología antropológica para el sondeo contemporáneo a través de encuestas a artistas de Huamanga que, en el caso de los talladores de Niño Rumi (alabastro o piedra de Huamanga) se concentran en el barrio de Santa Ana; mientras que los artistas de la madera son del barrio de San Juan Bautista. Si bien ambos casos se hallan insertos en un circuito económico local, nacional e internacional que los hace depender del crédito de instituciones estatales y/o particulares; en el aspecto de la preservación y puesta en valor de la tradición ancestral, los artistas en piedra de Huamanga no se han alejado de su corpus histórico y son continuadores de la talla a mano, de alta calidad estética y trasmisores de su cosmos circundante. El caso de la talla en madera es diferente, pese a su alta especialización, esta ha transitado de la actividad artesanal a la de tipo industrial. Un punto contrastante en este tipo de Arte, es que por un lado es un gremio sólido no dependiente del intermediario pero, a contraparte enfrenta el grave problema de la deforestación indiscriminada y por ende la desaparición de la oralidad en torno a la flora y a la fauna de su medio geográfico.

\subsubsection{Tablas de Sarhua de Carmelón Berrocal}

Con Carmelón Berrocal el SHRA abre una etapa en la que se planteaba la incorporación de artistas del ande peruano en el área de investigación histórica. Esta propuesta de Pablo Macera incluía avalar la participación de los artistas en el exterior, y fue así como en 1997 se tramitó la participación de Jesús Urbano Rojas y de Carmelón Berrocal al XXXIII Festival Internacional de Aarhus, Dinamarca. Berrocal tuvo la oportunidad de mostrar sus tablas genealógicas pintadas, las que forman parte de la estructura del techo en las casas de Sarhua, en las alturas de Víctor Fajardo (Ayacucho), de donde el artista es oriundo; además de haber llevado otro conjunto de tablas pintadas asociadas a cuentos y relatos de la flora y fauna de su pueblo. Con dichos materiales se organizó un libro a manera de catálogo que fue repartido en dicho evento. ${ }^{50}$

Berrocal constituye uno de los pintores populares del cual se han publicado una serie representativa de narrativas gráficas, cuya contribución a la educación intercultural y bilingüe se trasunta en sus cuentos presentados en Quechua Ayacucho Chanca -y sus variantes Cusco Collao y Áncash Huaylas- y en Aimara, además de su libro Flora y Fauna de Sarhua publicado en quechuañol. Su obra se halla expuesta en el Museo del Banco Central de Reserva, del centro histórico de Lima. Su temprana muerte en 1998, dejó en el tintero una serie de relatos pintados aún por publicar, en torno a la tradición textil, al curanderismo, los juegos tradicionales, las fiestas, los instrumentos musicales, entre otros aspectos.

En el año 2010, Pablo Macera reproduce en homenaje a Carmelón Berrocal, dos textos de su autoría, el primero correspondiente a la exposición homenaje realizado en el Museo de la Cultura peruana en 1998, y el segundo el texto introductorio del libro Flora y Fauna. Pintura y Palabra (textos en quechuañol). En ambos, Macera resalta la doble función del Arte de Berrocal que fue el "formar parte de una tradición y a la vez renovarla". ${ }^{51}$

48 Luján, 1987.

49 Luján, 1987.

50 Andazabal, 1997

51 Macera, 2010. 


\subsubsection{Fotografía y ritualidad}

A través de tres fotos reportajes Fredy Huamán Mallqui muestra dos aspectos de la cosmogonía surandina. El primero aborda la terapéutica tradicional (curación del susto de un infante sumergido en la panza de una vaca sacrificada en el camal de Huamanga), y el segundo se refiere a las fiestas religiosas de las cruces de Luricocha (Huanta, Ayacucho) y el de la peregrinación de la Virgen de Cocharcas (Apurímac). La fotografía es el recurso que emplea Huamán no sólo para perennizar imágenes etnográficas, sino también para deslizar un discurso crítico sobre la sociedad actual, el consumismo y la deshumanización. ${ }^{52}$

\subsection{Artesanía}

El estudio antropológico de Echeandía cubre un amplio espectro de la artesanía en el Bajo Piura, donde se toca varios aspectos del trabajo artesanal (técnicas, materias primas y el proceso de elaboración) del tejido, de la cerámica, de la sombrerería, de la orfebrería en filigrana de plata, del tallado en cuero y madera, del burilado y la carpintería metálica. A excepción de la última rama, todos los demás descienden de la tecnología ancestral de los Tallanes y Chusis. En la época de la Reforma Agraria, los artesanos estaban ya asociados en gremios, comercializando sus producciones artísticas en la zona y a nivel nacional, manejando capitales propios, casas comerciales, talleres y ayudantes a destajo, lo cual les permitía la reinversión de sus capitales, frente a otros sectores que aún hacían uso de los intermediarios. ${ }^{53}$

El ensayo de Antonio Rengifo, trata sobre el aporte de José Sabogal al conocimiento de la cultura andina. ${ }^{54}$ Mildred Merino, Pablo Macera y Gerardo Quiroz trabajaron una extensa lista bibliográfica sobre la artesanía peruana que muestra un abanico de temas como las ferias, las comunidades, el arte popular, el desarrollo artesanal por departamentos e informaciones sobre elementos mágicos religiosos, diccionarios y estampas; como también estudios antropológicos de danzas, textiles, mates y cerámica. ${ }^{55}$
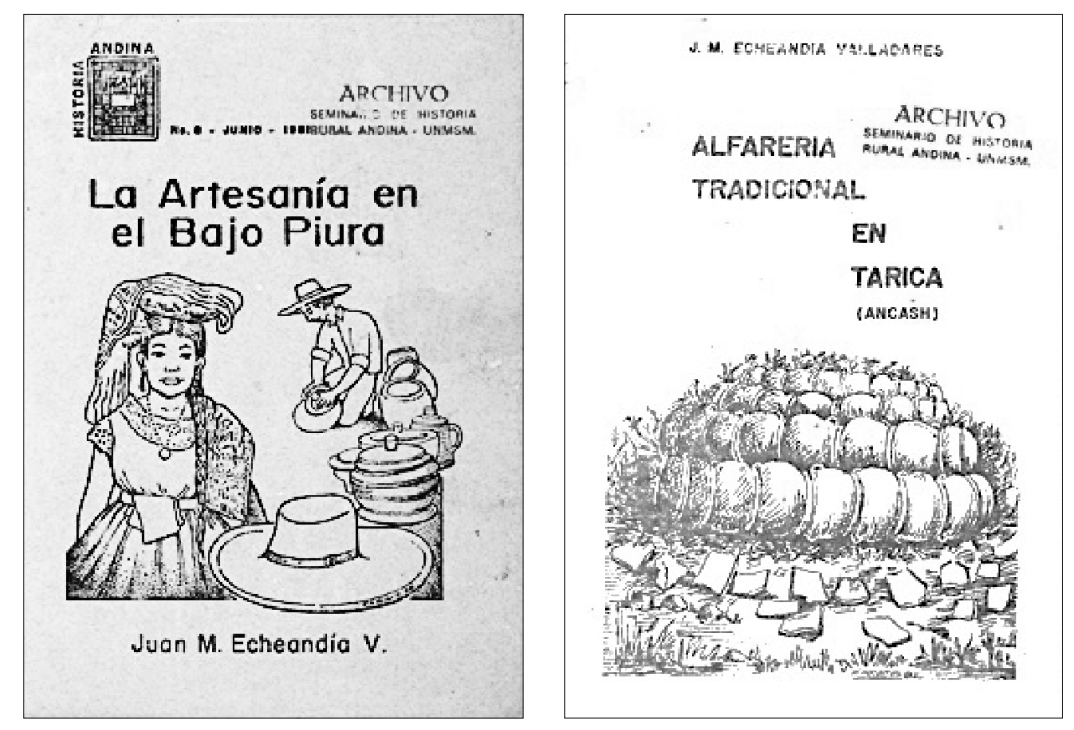

Andazabal, 2008.

Echeandía, 1981.

Rengifo, 1983.

Merino, Macera y Quiroz, 1984. 
Junto a estas investigaciones está la que trata sobre utensilios de junco y mimbre de larga data vinculada a sociedades ágrafas. Durante la colonia éstas fueron producidas de manera clandestina por negros cimarrones, con el fin de obtener recursos pecuniarios que les permitiera, entre otras cosas, huir de las haciendas donde eran explotados. En esos tiempos y después en la república el uso de cestos se circunscribió al entorno doméstico, extendido luego a los sectores agrícola y pesquero. En este contexto se inscribe la investigación de Jaime Miasta y Esperanza Soto, en torno a los artesanos del sureste de Lima Metropolitana ubicados entre el pueblo de Sisicaya y el distrito de Cieneguilla, cuya productividad estaba manejada por familias locales y foráneas, y confeccionaban cestos desde una gama burda hasta otras de alta sofisticación para el comercio local y nacional. ${ }^{56}$

\subsection{Alfarería}

Gerardo Quiroz aborda la tradición alfarera del pueblo de Santo Domingo de los Olleros, un pueblo de especialistas que fue constituido por una misión dominica en 1611. Este pueblo desarrolló su potencial productivo sobre la base de tecnología propia adaptada al nuevo estilo español. Quiroz, perfila el circuito de intercambio interzonal, la técnica y el estilo decorativo, como también las innovaciones promovidas por la cercanía del mercado urbano. ${ }^{57}$

El estudio antropológico de Juan Echeandía, por otro lado, trata sobre la situación contemporánea de la alfarería en San Jerónimo de Taricá, en el valle de Santa, Áncash. Muestra cómo la alfarería -de data pre inca-emerge durante la reforma agraria como principal fuente de trabajo al entrar en declive tanto la agricultura como la ganadería, debido a la escasez de agua, al autoconsumo y a rezagos semifeudales como la aparcería. En este contexto geográfico, favorecido por la presencia de vetas de arcilla y caolín, predomina la cerámica utilitaria, a excepción de algunas familias que reproducen modelos sofisticados de las culturas Nasca, Chavín, Chimú o Mochica. ${ }^{58}$

Junto a Renate Wisbar, Juan Echeandía investiga la productividad alfarera de Piura, cuyo registro histórico está asociado a la cultura Vicús, desarrollada por los artesanos contemporáneos del Bajo Piura, los de Chulucanas, Catacaos y Simbilá.59

\subsection{Juego tradicional}

Edmundo Motta muestra como en la Arequipa del siglo XIX, el juego de toros, a diferencia de Lima y otras provincias, fue impulsada en medio de encarnizadas disputas por la burguesía agroganadera de Juli, cuyo triunfo hasta épocas recientes era sellado de manera simbólica a través de la concesión de un astero de plata, lo que afirmaba el poder y status del vencedor. ${ }^{60}$

A Rubén Huapaya le tomó varios años el rescate y recopilación del juego de la pita. Su investigación identifica sus antecedentes históricos en las líneas de Nazca las que habría funcionado bajo el sistema de estaquería asociada a la astronomía, y cuya vigencia se mantiene aún hoy en día y que publica como material lúdico y didáctico para profesores y alumnos en edad escolar. ${ }^{61}$

\footnotetext{
56 Miasta, y Soto, 1987.

57 Quiroz, 1981.

58 Echeandía, 1982.

59 Echeandía, y Wisbar, 1990.

60 Motta, 1982.

61 Huapaya, 1996.
} 


\subsection{Pieles y cueros}

Los manuales para el uso de artesanos de pieles, es trabajado por Zivana Meseldzic con el objetivo de coadyuvar al seguimiento correcto del tratamiento del curtido y sus insumos. Perfila con juicio crítico el proceso extractivo de las pieles y cueros en el Perú, que durante la colonia estuvo monopolizado por regidores y eclesiásticos. Durante la República, desde el Estado se facilitó el ingreso de inmigrantes europeos, concediéndoseles garantías para el ejercicio de esta industria, lo que tendió a solidificar la economía de estos inversionistas, quienes tuvieron además acceso a extensos terrenos para la producción de arroz y algodón. La libre exportación dada en 1864 por el gobierno de J.A. Pezet, favoreció a nuevos inmigrantes europeos que hacia 1881 obtuvieron la concesión de tierras de montañas y la creación de las Aduanas de Loreto y el Amazonas, que les facilitaba sus operaciones comerciales. ${ }^{62}$

\subsection{Gráfica de la plástica andina}

En el libro Breve historia gráfica de la plástica andina, Juan Zárate elabora este registro plástico a mano alzada, tomando como punto de referencia piezas de arte popular peruano (cerámica, mate burilado, platería, keros y piedra de Huamanga) correspondientes a la colección del Museo de Arte de la UNMSM y de dos colecciones particulares, con las que Sirley Ríos realiza el estudio introductorio. ${ }^{63}$

\section{El atisbo de la oralidad en la serie La Quillca: Cotidianeidad y cosmogonía en el Ande cajamarquino (1975-1993)}

La mirada hacia la oralidad andina no es de interés reciente en las investigaciones del historiador Pablo Macera y el SHRA. Desde la década de 1970 ha tenido una activa participación en numerosas investigaciones y exposiciones sobre el arte y la oralidad andina con diversas instituciones limeñas, como la Galería de Arte Huamanqaqa de Raúl Apesteguía, o con el Museo Nacional de la Cultura Peruana, por citar algunos.

De igual modo puede verse en la producción bibliográfica del SHRA cómo hay un espacio importante para el tema de la oralidad. Este se inicia en 1975 con la publicación de Poncho Prieto, que narra la historia del pueblo de Sartimbamba, provincia de Sánchez Carrión, en el departamento de la Libertad. Su autor fue Prisciliano Infantes Saavedra, quien nació en Sartimbamba en 1917 y fue maestro carpintero en el Colegio Real de San Felipe de la UNMSM desde los años setenta al noventa. Precisamente en ese local se ubican las oficinas del SHRA y Macera a través de este cuento huamachuquino impulsa la serie La Quillca con el apoyo de la Dirección de Proyección Social de la universidad San Marcos, y "destinada a recoger testimonios del arte oral andino y a promover las realizaciones creadoras de los trabajadores del Perú”. Precisamente Macera recoge este testimonio de Prisciliano quien había 
escuchado este relato de sus abuelos, a través de su madre doña Petronila Saavedra [...] donde se hablaba del bien y del mal, de los campesinos y el hacendado, del oro y la tierra, enmarcado en un escenario de conflicto donde la promesa incumplida se sancionaba con el castigo. ${ }^{64}$

Esta serie trata sobre diversos aspectos de la vida cotidiana de Sartimbamba, y casi todas las publicaciones aparecidas bajo los títulos: Relatos (1977), El Cayhuas y la sierpe (1979), Mi pueblito Sartimbamba (1983) y Poemas (1993), son de autoría de Prisciliano Infantes, excepto La Bruja y el Satán recogida por Manuel Carbajal Miranda (1982).

La oralidad de Prisciliano Infantas nos transporta al imaginario colectivo rural de la sierra norte del Perú, donde sitúa las fiestas patronales, los juegos de gallos y el trabajo agrícola; pero también narra la historia local destacando personalidades -como el literato Ciro Alegría, el curandero Roberto Franco o la bióloga Juana Gregoria Infantes Vera- y hechos socio-políticos como la presencia de montoneros que acechaban a la población. Junto a esa narrativa cotidiana, histórica y geográfica, le suma aquella que la cosmovisión local traduce en cuentos y relatos en torno a la muerte y su asociación con seres sobrenaturales (fetos amorfos, sirenas, duendes, gatos) y fenómenos atmosféricos.

Con esta serie, el historiador Pablo Macera rescata la oralidad como patrimonio inmaterial de esa parte de nuestro territorio, para salvaguardarla, preservarla y ponerla en valor a través de la voz de Prisciliano Infantas que, se hace tangible en sus publicaciones con el SHRA.

La oralidad sola figura en casi toda la serie, tanto en los interiores como en las tapas de los libros de don Prisciliano, aunque ya se observa en Poncho Prieto que, en la contratapa hay un plano antiguo de 1792 del Virreinato del Perú para asociar la narrativa al contexto peruano; vinculante sí, pero genérico. En ese sentido, el libro Mi pueblito Sartimbamba es diferente. La carátula principal lleva impreso el dibujo a mano alzada del artista plástico Juan Zárate, efectuada en base a una fotografía facilitada por el autor de la obra, creando una asociación más directa con el relato interno, según refrendan las siguientes imágenes.
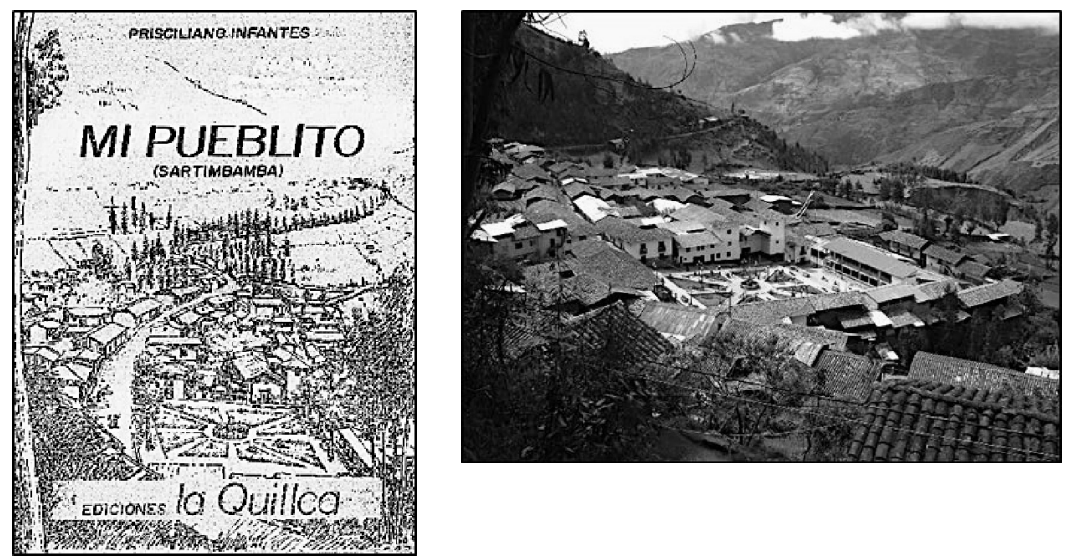

Fue evidente por entonces la necesidad de establecer un nexo armónico entre la oralidad y la imagen. Para ese trabajo, Pablo Macera convoca a dibujantes de la Escuela Nacional de Bellas Artes, de la Facultad de Arte de la Pontificia Universidad Católica del Perú y de autodidactas. Estos artistas realizaron dibujos asociadas a la narrativa y al arte andino. Así, por ejemplo, el trazo

64 Macera, en Infantes 1975: I. 
burilado de los dibujos que van impresos en los mates fue trasladado a mano alzada a algunas carátulas de libros. Así, la portada de La Bruja y el Satán, lleva el diseño de mujeres que caminan cargando a sus bebés sobre sus espaldas, junto a una fauna propia de la ceja de selva y en la contraportada se dibujó un escenario serrano de la que emerge un fino silueteado de pastores con sus ovejas, músicos y hombres a caballo.
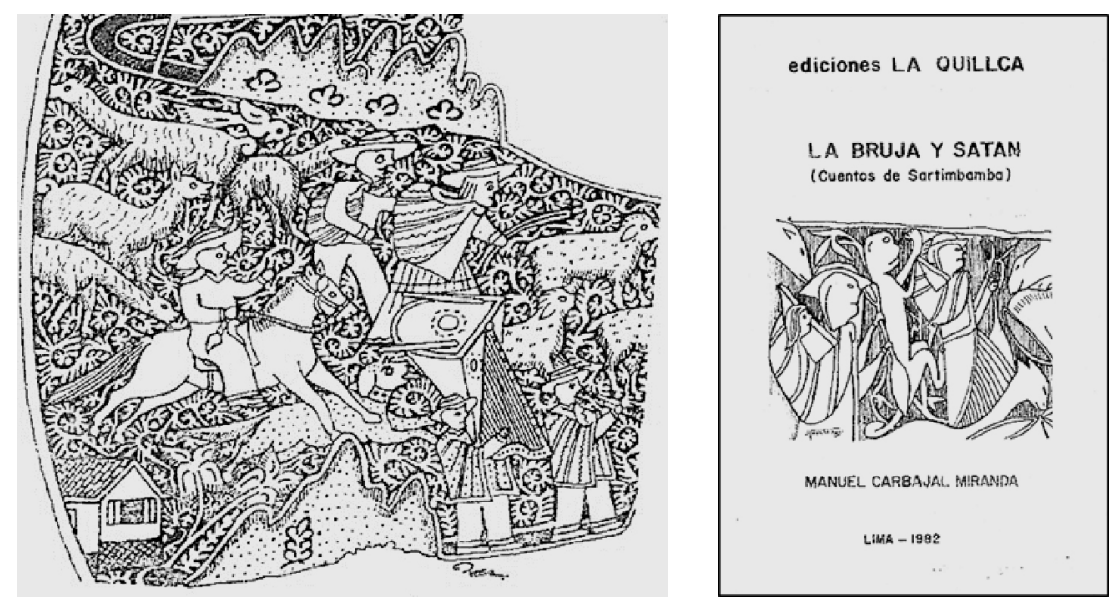

DIBUJANTES DEL SHRA 65

\begin{tabular}{|c|c|c|}
\hline N. ${ }^{\circ}$ & Nombres y apellidos del dibujante & Firma de identificación \\
\hline 1 & -- & A.S.L. \\
\hline 2 & Doris A. Huamán Baquerizo & -- \\
\hline 3 & Fernando Herrera García & F. H. G. \\
\hline 4 & Gredna Landolt & -- \\
\hline 5 & Isaías Ojeda Navarro & Khucho \\
\hline 6 & 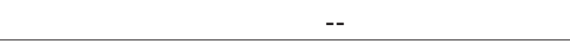 & J. L. A. \\
\hline 7 & Jori Sagastizábal Quispe & -- \\
\hline 8 & José Carnero Albarrán & Lalo \\
\hline 9 & Juan Antonio Valdivieso Fuente & Janto \\
\hline 10 & Juan Zárate & J. Z. \\
\hline 11 & Lucila Salguero N. & -- \\
\hline 12 & Lucy Jochamowitz & L. J. \\
\hline 13 & M. López Machiavelo & M. L. M. \\
\hline 14 & Manuel Caderón & J. M. C. \\
\hline 15 & Martha Monge & M. M. \\
\hline 16 & Óscar Casquino & -- \\
\hline 17 & Rosa M.S. & -- \\
\hline 18 & Rosario López Machiavello & Charo o R. L. M. \\
\hline 19 & Roxana Villalobos & R. V. M. \\
\hline 20 & Rubén Navarro V. & -- \\
\hline 21 & Tito Alfredo Enciso B. & T. E. B. \\
\hline 22 & Vicente Mendoza Jiménez & V. M. J. \\
\hline
\end{tabular}

Elaboración: Rosaura Andazabal

65 Los dibujantes firmaban sus obras con sus iniciales. Estos han sido descifrados por el propio Pablo Macera y varios miembros del SHRA como Miguel Pinto, Yolanda Candia y Juan Zárate. En base a esta información se ha podido elaborar el presente cuadro que va en orden alfabético. 


\section{Cuentos Pintados del Perú: Área Andina (1994-2015) ${ }^{66}$}

El proyecto Cuentos Pintados del Perú, creado y dirigido desde 1994 al presente por Pablo Macera, ha incidido en el fomento y desarrollo de la educación intercultural y bilingüe a través de la recopilación de cuentos tradicionales del Ande (Ayacucho, Puno, Áncash, Cusco), de la Amazonia (Shipibo, Bora, Asháninca, Aguaruna) y de los hijos de migrantes de colegios públicos de Lima. Trabajado por el área de historia del SHRA, a cargo de Rosaura Andazabal para el lado Andino y la Amazonia por María Belén Soria, contó además con la valiosa colaboración externa de la docente y lingüista Idelsa Mestas Delgado y del antropólogo Javier Macera Urquizo. El soporte principal fue el concurso activo de pintores y narradores autodidactas, quienes produjeron relatos orales asociados a la concepción propia de las cosmogonías locales de sus lugares de origen que, se complementan con la belleza plástica de pinturas elaborados por ellos mismos.

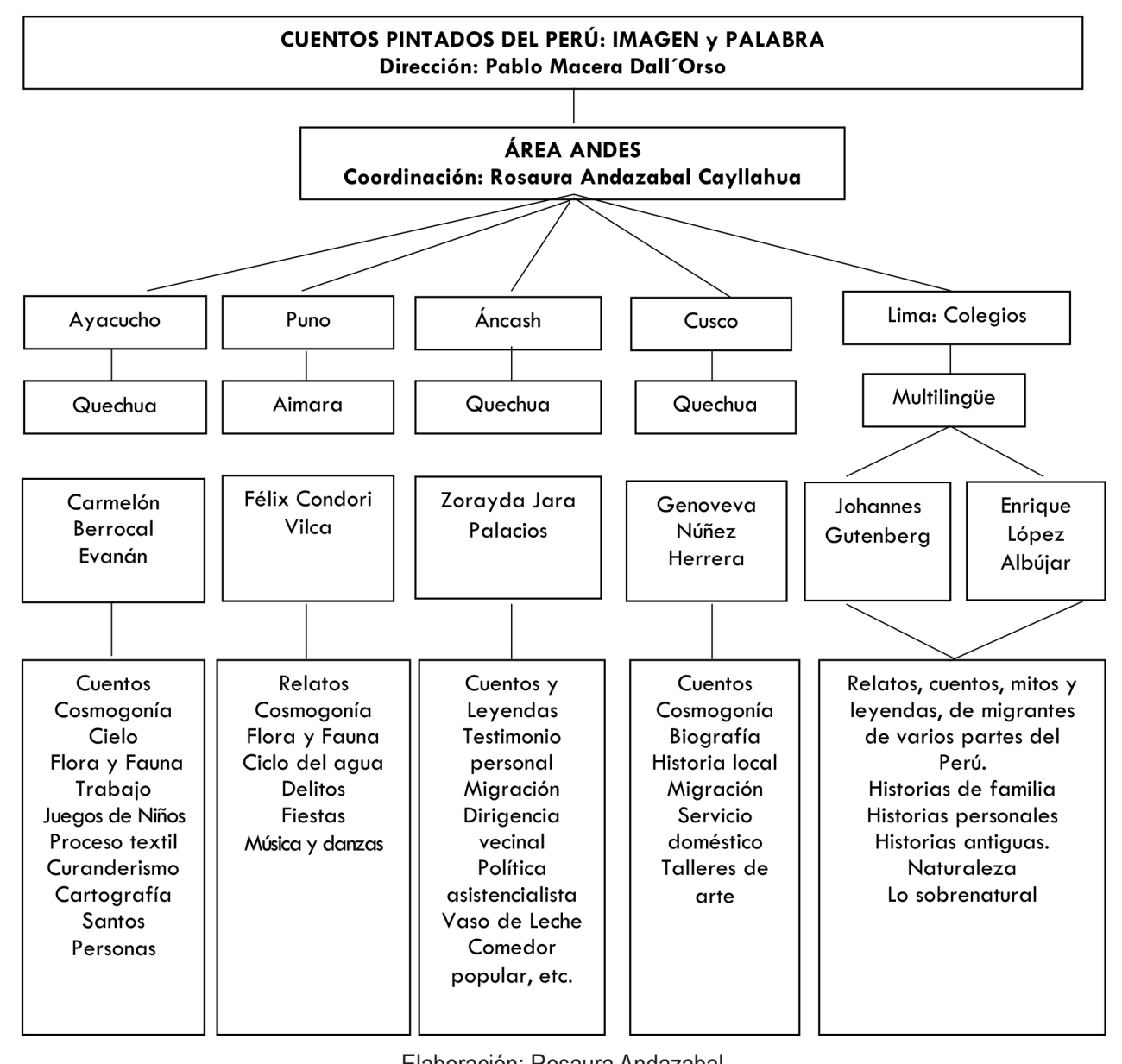

Elaboración: Rosaura Andazabal

En casi ya tres décadas este proyecto ha recopilado diversos registros plásticos que han ido de la mano con la oralidad propia de hombres y mujeres del Ande peruano. Obras de artistas populares que a decir del propio Pablo Macera "construyen un espacio propio, y obtienen con

66 Andazabal 2014: 269. 
limitaciones, un reconocimiento justo, dentro y fuera de ese cuarto mundo que opera al interior del tercer mundo." ${ }^{67}$

En esta área Andina, han participado y participan artistas migrantes de habla Quechua y Aimara establecidos con sus familias en los conos de Lima Metropolitana, que son los casos de Carmelón Berrocal, Félix Condori, Zorayda Jara y Genoveva Núñez, lo cual ha facilitado el desarrollo de nuestro trabajo mutuo. Artistas que han innovado sus tradiciones sin dejarse avasallar por ese monstruo tecnológico que viene del primer mundo, manteniendo sus identidades a través de códigos orales, pictóricos y musicales. Delineamos a continuación una breve referencia biográfica de los artistas que han trabajado en el proyecto, así como de los escolares de los colegios de Alto Huampaní (Chaclacayo) y del distrito El Agustino.

\subsection{Carmelón Berrocal: Arte, historia y tradición de Sarhua (Ayacucho 1964-1998)}

Gran Maestro de la Pintura y narrativa del distrito de Sarhua, la obra de Carmelón Berrocal, destaca por haber innovado la pintura tradicional de las tablas genealógicas familiares, con una propuesta plástica asociada a la narrativa que, produjo una rica galería iconográfica en torno a cuentos, a los juegos de niños y al mundo natural de las plantas y animales. Desde 1994 trabajó en el proyecto de Pablo Macera Cuentos Pintados del Perú. Habiendo sido su obra vista en el XXXIII Festival Internacional de Aarhus (Dinamarca, 1997), y que de forma permanente puede verse en el centro histórico de Lima, en el Museo del Banco Central de Reserva del Perú. Desde 1996 a la fecha tiene publicados junto al proyecto un conjunto de veinte libros de cuentos en Español/ Quechua (Ayacucho Chanca, Cusco Collao y Áncash Huaylas) y Español/ Aimara. En Quechuañol se ha publicado en el año 2002 Flora y Fauna de Sarhua.

\subsection{Félix Condori Vilca: Lagos, demonios y serpientes en la cosmogonía vilqueña (Puno 1973)}

Félix Condori Vilca es un pintor aimara cuya obra refleja la Cosmogonía del distrito de Vilque Chico, en la provincia de Huancané. Ésta se encuentra asociada a la vida cotidiana y a las celebraciones rituales en el que confluyen seres mitológicos cómo la gran serpiente, los niños diablos o los hombres mulas. Su obra se ha expuesto en "Mitos, ritos y pagos" (Telefónica, 1999), "Matices de mi tierra" (INC/ EDELNOR, 2000); "Madres y Niñas” (UNESCO/SHRA-UNMSM, 2001), "Vivencia Aimara" (Museo de Arte/ SHRA-UNMSM, 2000) y "Lagos, demonios y serpientes" (SHRA-UNMSM, 2002). Su Arte ha sido difundido en calendarios interculturales editados por Tarea Gráfica Educativa, Care Perú y el SHRA. Ha publicado en el año 2002 su libro Lagos, demonios y serpientes (SHRA-UNMSM).

3.3 Zoraida Jara Palacios (Áncash, 1959): De las labores del campo en Huasta a la dirigencia vecinal en Pamplona Alta

Zoraida Jara Palacios es una dirigente comunal, Arpillera y pintora narradora. Su obra refleja el rol que ha desempeñado la mujer migrante andina en la urbe limeña del cono sur de Lima. Desde 1978 vive en Pamplona Alta, donde ha participado en talleres artesanales y de salud promovidos por varias ONGs. Su obra ha sido presentada en varias exposiciones cómo "Madres y Niñas"

67 Macera 2001: 37. 
(UNESCO/ SHRA-UNMSM, 2001), "Narración e imagen” (Museo Nacional de la Cultura Peruana-INC/ SHRA-UNMSM, 2003), "Zorayda Jara. Testimonio de vida” (SHRA-UNMSM, 2003), y en el "Día de la No Violencia familiar", en la Casa Manuela Ramos de San Juan de Miraflores, en noviembre del año 2003. Asimismo, ha participado en los calendarios interculturales y bilingües de Care Perú y del SHRA. Además de haber publicado su libro Zorayda Jara, testimonio de vida (SHRA-UNMSM, 2003).

\subsection{Genoveva Núñez Herrera (Ollantaytambo, 1939): De la hacienda Rumira a Huampaní Alto}

Genoveva Núñez Herrera es retablista e imaginera, narradora pintora. Su obra amalgama su biografía, la historia y la cosmogonía de las gentes de Lares, Ocobamba y La Convención. Narrativas gráficas que fueron apreciadas en su individual titulada "Tradición Oral del Valle del Ollantaytambo", presentado en la Sala de Exposiciones Colegio Real en el 2006. Ha ilustrado el libro Ganadores del II Concurso de Cuentos. En el Aniversario del chifa Wa Lok, en el año 2006. Ha dictado talleres de Retablos, Cajones San Marcos e imaginería tanto en el Museo de Arte de San Marcos (2007-2008), como en el ISHRA (2016). Su obra ha participado en otras exposiciones colectivas en la UNMSM, y en el Museo Nacional de la Cultura Peruana. Asimismo, en los calendarios del año 2002 de Tarea Gráfica Educativa y en el de Care Perú y el SHRA en el año 2009. Ha publicado el año 2012 en el SHRA su libro Cusco: Arte y Tradición Oral Quechua del Valle del Ollantaytambo.

3.5 Colegios de Lima Metropolitana: Hijos de migrantes del ande peruano asentados en los distritos de El Agustino y de Chaclacayo

\subsubsection{Colegio Enrique López Albújar}

En esta institución educativa N. ${ }^{\circ} 502$, ubicada en la primera zona del Asentamiento Humano Alto Huampaní, Chaclacayo, del distrito de Lurigancho, el SHRA desarrolló durante el año 2001 la revaloración de la oralidad asociada a la imagen con escolares de educación primaria. La mayoría de los alumnos eran hijos de migrantes de la provincia de Huanta, del departamento de Ayacucho, y en menor proporción de migrantes procedentes del norte y del centro peruano.

A diferencia del colegio Johannes Gutenberg, en esta institución pública se evidenciaba varias carencias de infraestructura y materiales de trabajo. Esto último fue asumido por el proyecto Cuentos Pintados del Perú que proporcionó a los alumnos participantes la logística requerida (hojas bond; lápices, plumones y lapiceros), con los cuales se pudo compilar un conjunto de cuentos, relatos y leyendas que fue acompañado por los dibujos de cada uno de los narradores. En esta fase también contamos con el trabajo multidisciplinario de la docente directora del Colegio, y los maestros de Arte y de Literatura que, se complementó con el apoyo del artista plástico Juan Zárate. ${ }^{68}$ Todos los niños participaron con sus dibujos y narraciones en la exposición colectiva Madres/ Niñas en diciembre de 2001, con la que se inaugura la Sala de Exposiciones Colegio Real, siendo director del SHRA, el arqueólogo Jaime Miasta Gutiérrez.

\subsubsection{Colegio Johannes Gutenberg}

Ubicado en la urbanización La Corporación, del distrito El Agustino, el Colegio Johannes Gutenberg brinda educación gratuita de calidad a niños de escasos recursos económicos, gracias

68 Este material está inédito, y es una deuda con dicho centro educativo que esperamos saldar en breve. 
al financiamiento de donaciones privadas de Alemania y Suiza. Se imparte educación integral científico-humanístico en los niveles de inicial, primaria y secundaria. Ya en secundaria se añade las especialidades técnicas: asistente de administración, confecciones industriales, electrotecnia, mecánica de producción y soldadura. ${ }^{69}$

En este colegio el SHRA trabajó con un grupo de niños entre ocho (90\%) y quince años (10\%), quienes, dirigidos por la artista plástica Gilma Concha Manrique, profesora del curso de Arte, demostraron su destreza plástica en el manejo técnico de óleos, témperas y lápices de colores. Además, en la recopilación de un conjunto de narraciones andinas, se tuvo la colaboración de la maestra de Literatura María del Rosario Segovia Tapia. La mayoría de estas narraciones provenían de regiones como Áncash, Cusco, Arequipa, Apurímac, Ayacucho y Puno, junto a otro conjunto que abarcó a algunas zonas norteñas de Cayaltí, Lambayeque y Piura. Un grupo mínimo se circunscribió a la periferia de los cementerios Presbítero Maestro y el Ángel, en los Barrios Altos de Lima; y finalmente dos relatos se refieren a nuestra Amazonia.

Esta presencia mayoritaria de narraciones andinas es un indicador de la procedencia de la población migrante del distrito del Agustino. Algunos interpretaron los relatos orales de los lugares de origen de sus abuelos, de sus padres, de familiares y de algunos de sus profesores. La temática alude a la cosmogonía andina que incide en historias personales, en leyendas e historias antiguas, sobre la naturaleza y lo sobrenatural. ${ }^{70}$

\section{Reflexiones finales}

El Seminario de Historia Rural Andina fundado a finales de la década del sesenta por el historiador Pablo Macera, ha marcado desde sus inicios al presente una producción bibliográfica multidisciplinaria de las Ciencias Sociales y Humanas. Investigaciones cimentadas bajo los ejes de la economía, la sociedad y el arte, tendiendo a visibilizar un derrotero que ha transitado entre varios sub-ejes de estudio, como el que es posible ver en el tránsito de la oralidad pura a la armoniosa fusión que subyace entre el arte y la oralidad, donde se recogen las voces y el gusto estético de las poblaciones del ande peruano, cuyo devenir histórico se halla cimentado en una concepción cosmogónica cíclica.

En este sentido, la oralidad pura del poblador andino emerge desde la sierra norteña de Cajamarca a través de la edición La Quillca; para dar inmediato paso a una etapa -entre las décadas de los setenta y los noventa- donde el arte y la oralidad figuran en sendas publicaciones multidisciplinarias.

Finalmente, se halla con mayor énfasis, desde la década de los noventa, las narrativas gráficas que el proyecto Cuentos Pintados del Perú recopila de los maestros de nuestro Ande. Aquí la autobiografía se engarza al contexto histórico local de los pueblos andinos que confluyen en un entorno cosmogónico que nos traduce a una serie de híbridos personajes sobrenaturales, vinculados a otorgar poderes y riquezas; pero también para normar, encauzar y sancionar la conducta humana. Todo lo cual perfila el corpus general de una tradición oral quechua y aimara, que las gentes del Ande han sabido salvaguardar por generaciones, como tesoro intangible para todos los peruanos, y para compartirlos con todos los países de frontera y más allá, a la búsqueda de establecer nexos de educación multilingüe e intercultural.

69 Andazabal 2004: 6

70 Andazabal 2004: 9. 


\section{Bibliografía}

Andazabal Cayllahua, Rosaura (2015). "Rasu Bilca: Pervivencia histórica de una deidad del ande peruano en el imaginario religioso colectivo.”, pp. 133-162. En: Diana Araujo Pereira y Juan Pablo Martín Rodríguez (Org.). Imaginarios Coloniais: Continuidades e rupturas na América Latina Contemporânea. Sao Paulo: Portal Editora.

Andazabal Cayllahua, Rosaura y Omar, Rojas Herrera (2015). Indios, tierras y caciques del Perú, siglos XVIII-XIX, 2da. Edición. Lima: Archivo General de la Nación, Dirección Nacional de Archivo Histórico (Colección Guillermo Durand Flórez), Seminario de Historia Rural Andina, Universidad Nacional Mayor de San Marcos.

Andazabal Cayllahua, Rosaura (2014). “Cuentos Pintados del Perú: Memorias, imágenes y lenguas del Ande”, en: Diana Araujo Pereira (Org.). Cartografia Imaginária da Tríplice Fronteira. Sao Paulo: Dobra Editorial.

Andazabal Cayllahua, Rosaura (2006). Publicaciones. Seminario de Historia Rural Andina (19682000). Lima: Seminario de Historia Rural Andina, Universidad Nacional Mayor de San Marcos.

Andazabal Cayllahua, Rosaura (1994). Pleitos de tierras, Quito 1708-1716 (Anla y Cochecarangue). Lima: Seminario de Historia Rural Andina, Universidad Nacional Mayor de San Marcos.

Andazabal Cayllahua, Rosaura (1997). Retablos andinos/Ayacucho. Jesús Urbano Rojas. Lima: Seminario de Historia Rural Andina, Universidad Nacional Mayor de San Marcos.

Andazabal Cayllahua, Rosaura (1997). Tablas pintadas de Sarhua. Carmelón Berrocal Evanán. Lima: Seminario de Historia Rural Andina, Universidad Nacional Mayor de San Marcos.

Andazabal Cayllahua, Rosaura (2008). Fredy Huamán Mallqui. Ritualidad. Fotografía (catálogo). Lima: Seminario de Historia Rural Andina, Universidad Nacional Mayor de San Marcos.

Arroyo Aguilar, Sabino (1987). Algunos aspectos del culto al Tayta Wamani. Lima: Seminario de Historia Rural Andina, Universidad Nacional Mayor de San Marcos.

Arroyo Aguilar, Sabino (1988). Catequización y conflictos sociales en Guamanga. Lima: Seminario de Historia Rural Andina, Universidad Nacional Mayor de San Marcos.

Basto Girón, Luis (1977). Salud y enfermedad en el campesino peruano del siglo XVII. Lima: Seminario de Historia Rural Andina, Universidad Nacional Mayor de San Marcos.

Berrocal, Carmelón, Macera, Pablo; Andazabal, Rosaura (1997a). Cuentos pintados del Perú/Pirumanta llinpisqa willakuykuna. Sarhua n. ${ }^{\circ}$ 3. Lima: Seminario de Historia Rural Andina, UNMSM. Dirección Nacional de Formación y Capacitación Docente, Ministerio de Educación del Perú. Deutsche Gesellschaft Für Technische Zusammenarbeit (GTZ) GMBH.

Berrocal, Carmelón, Macera, Pablo; Andazabal, Rosaura (1997b). Cuentos pintados del Perúl Pirumanta llinpisqa willakuykuna. Sarhua (Español/Quechua Ayacucho Chanca) n. ${ }^{\circ}$. Lima: Seminario de Historia Rural Andina, UNMSM. Dirección Nacional de Formación y Capacitación Docente, Ministerio de Educación del Perú. Deutsche Gesellschaft Für Technische Zusammenarbeit (GTZ) GMBH.

Berrocal, Carmelón, Macera, Pablo; Andazabal, Rosaura (1997c). Cuentos pintados del Perú/Piruwata samichata jawarinaka. Sarhua (Español/Aimara) n. ${ }^{\circ}$ 5. Lima: Seminario de Historia Rural Andina, UNMSM. Dirección Nacional de Formación y Capacitación Docente, Ministerio de Educación del Perú. Deutsche Gesellschaft Für Technische Zusammenarbeit (GTZ) GMBH.

Candia Quispe, Yolanda (1998). Callao, 1633-1879. Lima: Seminario de Historia Rural Andina, 
Universidad Nacional Mayor de San Marcos,

Candia Quispe, Yolanda (2016). Publicaciones del SHRA: 2011-2015. (Catálogo inédito) Lima: Seminario de Historia Rural Andina, Universidad Nacional Mayor de San Marcos.

Carbajal C., Rubén (1981). Fiesta del Niño Perdido. Folklore musical de Huancavelica. Lima: Seminario de Historia Rural Andina, Universidad Nacional Mayor de San Marcos.

Carbajal Miranda, Manuel (1982). La bruja y el satán. (Cuentos de Sartimbamba), Ediciones La Quillca. Lima: Seminario de Historia Rural Andina, Universidad Nacional Mayor de San Marcos.

Carnero Albarrán, Nadia (1980). Mapas campesinos en Bolivia. Lima: Seminario de Historia Rural Andina, Universidad Nacional Mayor de San Marcos.

Condori, Félix y Rosaura Andazabal (2002). Lagos, Demonios y Serpientes. Narraciones aimaras. Lima: Seminario de Historia Rural Andina, Universidad Nacional Mayor de San Marcos.

Cuentas, Karina (2000). Esquemas visuales, dos experiencias de percepción. Lima: Seminario de Historia Rural Andina, Universidad Nacional Mayor de San Marcos.

Chávez Hualpa, Fabiola Yvonne (2004). Mamantin. El ciclo vital reproductivo de la mujer y el infante en los cronistas de los siglos XVI y XVIII. Lima: Seminario de Historia Rural Andina, Universidad Nacional Mayor de San Marcos.

Chávez Hualpa, Fabiola Yvonne (2005). Temas andinos. Mitología, Arqueología, Medicina tradicional y Fiestas. Lima: Seminario de Historia Rural Andina, Universidad Nacional Mayor de San Marcos.

Delgar, Martín (1980 [1800]). Libro de medicinas y cirugía. Para el uso de los pobres. Con su recetario al final. Compilación a cargo de Rosa Boccolini. Lima: Dirección de Proyección Social, Seminario de Historia Rural Andina, Universidad Nacional Mayor de San Marcos.

De la Cruz Fierro, Juan (1982). Folklore Andino I. Lima: Seminario de Historia Rural Andina, Universidad Nacional Mayor de San Marcos.

Echeandía Valladares, Juan Manuel (1981). Tecnología y cambios en la comunidad de San Pedro de Casta. Lima: Seminario de Historia Rural Andina, Universidad Nacional Mayor de San Marcos.

Echeandía Valladares, Juan (1981a). La artesanía en el Bajo Piura. Serie Historia Andina n. 8. Lima: Seminario de Historia Rural Andina, Universidad Nacional Mayor de San Marcos.

Echeandía Valladares, Juan (1982). La Isla Taquile. Agricultura, tejidos y diseños. Serie Historia Andina n. ${ }^{\circ}$ 13. Lima: Seminario de Historia Rural Andina, Universidad Nacional Mayor de San Marcos.

Echeandía Valladares, Juan (1982a). Alfarería tradicional en Taricá (Áncash). Serie Historia Andina n. ${ }^{\circ}$ 16. Lima: Seminario de Historia Rural Andina, Universidad Nacional Mayor de San Marcos.

Echeandía Valladares, Juan y Renate Wisbar (1990). Los ceramistas de Piura. Lima: Seminario de Historia Rural Andina, Universidad Nacional Mayor de San Marcos.

Espinosa Descalzo, Victoria (1999). Cartografía de Lima (1654-1893). Lima: Seminario de Historia Rural Andina, Universidad Nacional Mayor de San Marcos.

Espinosa Descalzo, Victoria (2001). Cartografía de Lima. Callao siglo XVIII. volumen II. Lima: Seminario de Historia Rural Andina, Universidad Nacional Mayor de San Marcos.

Galvez, José María y Pablo Macera (coord.) (1995). Santiago Mayor de Yanas (tríptico). Lima: Encuesta Pintura Mural Andina, UNESCO-Universidad Nacional Mayor de San Marcos.

Gushiken, José (1977). Tuno: El curandero. Prólogo de Carlos Alberto Seguín. Lima: Seminario de 
Historia Rural Andina, Universidad Nacional Mayor de San Marcos.

Gushiken, José (1979). El violín de Isua. Biografía de un intérprete de música folklórica. Lima: Seminario de Historia Rural Andina, Universidad Nacional Mayor de San Marcos.

Gushiken, José (1993). Extirpación de la idolatría en la sierra de Lima. Lima: Seminario de Historia Rural Andina, Universidad Nacional Mayor de San Marcos.

Hinostroza, Lauro (1988). Medicina andina. Lima: Seminario de Historia Rural Andina, Universidad Nacional Mayor de San Marcos.

Huapaya Amado, Rubén Darío (1996). El juego de la pita. Lima: Seminario de Historia Rural Andina, Universidad Nacional Mayor de San Marcos.

Jara Palacios, Zorayda y Rosaura Andazabal (2003). Testimonio de Vida. Lima: Seminario de Historia Rural Andina, Universidad Nacional Mayor de San Marcos.

Infantes Saavedra, Priciliano (1975). Poncho Prieto. Serie Ediciones La Quillca. Lima: Seminario de Historia Rural Andina, Universidad Nacional Mayor de San Marcos.

Infantes Saavedra, Priciliano (1977). Relatos. Serie Ediciones La Quillca. Lima: Seminario de Historia Rural Andina, Universidad Nacional Mayor de San Marcos.

Infantes Saavedra, Priciliano (1979). El cayhuas y la sierpe (cuentos). Serie Ediciones La Quillca. Lima: Seminario de Historia Rural Andina, Universidad Nacional Mayor de San Marcos.

Infantes Saavedra, Priciliano (1983). Mi pueblito (Sartimbamba). Serie Ediciones La Quillca. Lima: Seminario de Historia Rural Andina, Universidad Nacional Mayor de San Marcos.

Infantes Saavedra, Priciliano (1993). Poemas. Serie Ediciones La Quillca. Lima: Seminario de Historia Rural Andina, Universidad Nacional Mayor de San Marcos.

Lira, Jorge A. (1988). Himnos quechuas. Lima: Seminario de Historia Rural Andina, Universidad Nacional Mayor de San Marcos.

Luján, Flor (1987). Artesanía en piedra de Huamanga. Lima: Seminario de Historia Rural Andina, Universidad Nacional Mayor de San Marcos.

Luján Vargas, Mary (1987). Artesanía en madera (Huamanga-Ayacucho). Lima: Seminario de Historia Rural Andina, Universidad Nacional Mayor de San Marcos.

Macera, Pablo (1968). Mapas coloniales de haciendas cuzqueñas. Lima: Seminario de Historia Rural Andina, Universidad Nacional Mayor de San Marcos.

Macera, Pablo (1980). Arte y lucha social: Los murales de Ambaná (Bolivia). Lima: Seminario de Historia Rural Andina, Universidad Nacional Mayor de San Marcos.

Macera, Pablo (1981). Retablos andinos. Serie Historia Andina n. ${ }^{\circ}$ 4. Lima: Seminario de Historia Rural Andina, Universidad Nacional Mayor de San Marcos.

Macera, Pablo (1981). Joaquín López Antay. Serie Historia Andina n. ${ }^{\circ}$ 9. Lima: Seminario de Historia Rural Andina, Universidad Nacional Mayor de San Marcos.

Macera, Pablo (1988). Mojos y Chiquitos, 1768-1820, Biblioteca Andina, Fuentes de Historia Social Americana, volumen XI, tomo I. Lima: Seminario de Historia Rural Andina, Universidad Nacional Mayor de San Marcos.

Macera, Pablo (1988). Mojos y Chiquitos, 1825-1856. Biblioteca Andina, Fuentes de Historia Social Americana, volumen XII, tomo II. Lima: Seminario de Historia Rural Andina, Universidad Nacional Mayor de San Marcos.

Macera, Pablo (1989). Imágenes de Bolivia, 1765-1857. Fuentes de Historia Social Americana, volumen 16. Lima: Seminario de Historia Rural Andina, Universidad Nacional Mayor de San Marcos.

Macera, Pablo (1991). Caminos de Bolivia, 1765-1843. Fuentes de Historia Social Americana, 
volumen 20, Lima: Seminario de Historia Rural Andina, Universidad Nacional Mayor de San Marcos.

Macera, Pablo (2010). Carmelón Berrocal Evanán (Sarhua: 1964-1998) (folleto). Lima: Seminario de Historia Rural Andina, Universidad Nacional Mayor de San Marcos.

Macera Urquizo, Javier (2004). El curanderismo en las comunidades de Mórrope y Salas. Lima: Seminario de Historia Rural Andina, Universidad Nacional Mayor de San Marcos.

Mallma Cortez, Arturo Luis (1989). Los Mitmaq Yauyos en el Reyno Wanka. Lima: Seminario de Historia Rural Andina, Universidad Nacional Mayor de San Marcos.

Mallma Cortez, Arturo y Rufino Torres Pianto (2009). Origen e interpretación iconográfica del símbolo de la Universidad Nacional del Centro del Perú. Lima: Seminario de Historia Rural Andina, Universidad Nacional Mayor de San Marcos.

Merino, Mildred; Pablo Macera y Gerardo Quiroz (1984). Fuentes bibliográficas para la artesanía del Perú, 1982. Lima: Seminario de Historia Rural Andina, Universidad Nacional Mayor de San Marcos.

Meseldzic, Zivana (1998). Curtido de pieles. Manual elemental. Lima: Seminario de Historia Rural Andina, Universidad Nacional Mayor de San Marcos.

Meseldzic, Zivana (2000). Pieles y cueros del Perú republicano. Tomo III. Lima: Seminario de Historia Rural Andina, Universidad Nacional Mayor de San Marcos.

Miasta Gutiérrez, Jaime y Esperanza Soto Boada (1987). La cestería urbano marginal de LimaCieneguilla. Lima: Seminario de Historia Rural Andina, Universidad Nacional Mayor de San Marcos.

Morande, Pedro (1980). Ritual y palabra (Aproximación a la religiosidad popular latinoamericana). Lima: Seminario de Historia Rural Andina, Universidad Nacional Mayor de San Marcos.

Motta Zamalloa, Edmundo (1985). El Agua, la serpiente y la Candelaria de Arequipa. Lima: Seminario de Historia Rural Andina, Universidad Nacional Mayor de San Marcos.

Motta Zamalloa, Edmundo (1987). De Morenos y Cruceros. Religiosidad popular, intercambio y cosmovisión andina. Lima: Seminario de Historia Rural Andina, Universidad Nacional Mayor de San Marcos.

Motta Zamalloa, Edmundo (1982). El Astero de Plata. Lima: Seminario de Historia Rural Andina, Universidad Nacional Mayor de San Marcos.

Núñez Herrera, Genoveva y Rosaura Andazabal (2012). Cusco: Arte y tradición oral quechua del valle del Ollantaytambo. Lima: Seminario de Historia Rural Andina, Universidad Nacional Mayor de San Marcos.

Peralta Apaza, Luz (2002). Pleito de tierras en Ámbar. Cajatambo, siglo XVIII. Lima: Seminario d Historia Rural Andina, Universidad Nacional Mayor de San Marcos.

Peralta Apaza, Luz (2014). Imagen de la mujer en la publicidad gráfica de la prensa limeña, 19502000. Lima: Seminario de Historia Rural Andina, Universidad Nacional Mayor de San Marcos.

Pinto Herrera, Honorio (2011). Seminario de Historia Rural Andina. Publicaciones 2001-2010. Lima: Seminario de Historia Rural Andina, Universidad Nacional Mayor de San Marcos.

Polia Meconi, Mario (2005). Glosario del Curanderismo Andino en el Departamento de Piura (Perú). Lima: Seminario de Historia Rural Andina, Universidad Nacional Mayor de San Marcos.

Prada, Felícita y María Vergara (1984). Retablo ayacuchano. Serie Historia Andina n. ${ }^{\circ}$ 17. Lima: 
Seminario de Historia Rural Andina, Universidad Nacional Mayor de San Marcos.

Quirita, Alicia (1995). Cuzco: Espinar (Coporaque, Pichigua, Occoruro, Condoroma, Héctor Tejada, Yauri). Informe n. ${ }^{\circ}$, Encuesta pintura mural andina. Lima: UNESCO, Seminario de Historia Rural Andina, Universidad Nacional Mayor de San Marcos.

Quiroz Chueca, Gerardo (1981). La tradición alfarera en Santo Domingo de los Olleros. Serie Historia Andina n. ${ }^{\circ}$ 10. Lima: Seminario de Historia Rural Andina, Universidad Nacional Mayor de San Marcos.

Quiroz, Haydeé; Elena Rivas y Gladys Guerra (1978). La artesanía textil en San Miguel de Pallaques. Lima: Seminario de Historia Rural Andina, Universidad Nacional Mayor de San Marcos.

Rengifo, Antonio (1983). El artesano caracterizado por José Sabogal Wiesse (Un ensayo de interpretación). Serie Historia Andina n. ${ }^{\circ}$ 19. Lima: Seminario de Historia Rural Andina, Universidad Nacional Mayor de San Marcos.

Robles Mendoza, Román (1982). Quipu y Mashas en la comunidad de Mangas. Lima: Seminario de Historia Rural Andina, Universidad Nacional Mayor de San Marcos.

Rodas Rodas, Fredy (1994). Andahuaylas (Andarapa, Pacucha, Huancaray, Turpo). Informe n. ${ }^{\circ} 1$, Encuesta pintura mural del Perú. Lima: UNESCO, Seminario de Historia Rural Andina, Universidad Nacional Mayor de San Marcos.

Rodas Rodas, Fredy (1994). Tejidos tradicionales de Andahuaylas. Lima: Seminario de Historia Rural Andina, Universidad Nacional Mayor de San Marcos.

Rojas Herrera, Omar (1994). Hatos y tierras de Burgay, Quito (Siglo XVIII). Lima: Seminario de Historia Rural Andina, Universidad Nacional Mayor de San Marcos.

Salinas, Alejandro y María Belén Soria (1994). Tierras y estancias de Chile Colonial, siglo XVIII. Lima: Seminario de Historia Rural Andina, Universidad Nacional Mayor de San Marcos.

Sayan Pizzali, Guillermo (1981). Los maquitos (significado del diseño textil). Serie Historia Andina n. ${ }^{\circ}$ 6. Lima: Seminario de Historia Rural Andina, Universidad Nacional Mayor de San Marcos.

Tácunan Bonifacio, Santiago (1999). Mojos y Chiquitos (1825-1844). Biblioteca Andina, Fuentes de Historia Social Americana, tomo III, volumen XXV. Lima: Seminario de Historia Rural Andina. Universidad Nacional Mayor de San Marcos.

Valencia Espinoza, Abraham (1987). La Wak’a de Suyu. Una Deidad Andina en plena función. Lima: Seminario de Historia Rural Andina, Universidad Nacional Mayor de San Marcos.

Varios autores y Rosaura Andazabal Cayllahua (coord.) (2004). Me contó mi abuelita este cuentito que he pintado. Lima: Colegio Johannes Gutenberg, Tarea Asociación Gráfica Educativa, Seminario de Historia Rural Andina, Universidad Nacional Mayor de San Marcos.

Zárate Cuadrado, Juan y Sirley Ríos Acuña (2001). Breve Historia Gráfica de la Plástica Andina. Dibujos I. Lima: Seminario de Historia Rural Andina, Universidad Nacional Mayor de San Marcos.

Fecha de recepción: 29/VIII/2016

Fecha de aceptación: 30/IX/2016 